\title{
Review Article \\ Cancer Stem Cell Quiescence and Plasticity as Major Challenges in Cancer Therapy
}

\author{
Wanyin Chen, Jihu Dong, Jacques Haiech, Marie-Claude Kilhoffer, and Maria Zeniou
}

Laboratoire d'Innovation Thérapeutique, Université de Strasbourg/CNRS UMR7200,

Laboratoire d'Excellence Medalis, Faculté de Pharmacie, 74 route du Rhin, 67401 Illkirch, France

Correspondence should be addressed to Maria Zeniou; zeniou@unistra.fr

Received 16 March 2016; Accepted 15 May 2016

Academic Editor: Javier Garcia-Castro

Copyright (C) 2016 Wanyin Chen et al. This is an open access article distributed under the Creative Commons Attribution License, which permits unrestricted use, distribution, and reproduction in any medium, provided the original work is properly cited.

Cells with stem-like properties, tumorigenic potential, and treatment-resistant phenotypes have been identified in many human malignancies. Based on the properties they share with nonneoplastic stem cells or their ability to initiate and propagate tumors in vivo, such cells were designated as cancer stem (stem-like) or tumor initiating/propagating cells. Owing to their implication in treatment resistance, cancer stem cells (CSCs) have been the subject of intense investigation in past years. Comprehension of CSCs' intrinsic properties and mechanisms they develop to survive and even enhance their aggressive phenotype within the hostile conditions of the tumor microenvironment has reoriented therapeutic strategies to fight cancer. This report provides selected examples of malignancies in which the presence of CSCs has been evidenced and briefly discusses methods to identify, isolate, and functionally characterize the CSC subpopulation of cancer cells. Relevant biological targets in CSCs, their link to treatment resistance, proposed targeting strategies, and limitations of these approaches are presented. Two major aspects of CSC physiopathology, namely, relative in vivo quiescence and plasticity in response to microenvironmental cues or treatment, are highlighted. Implications of these findings in the context of the development of new therapies are discussed.

\section{Scope of This Review}

Many if not most cancers are characterized by the presence of a subpopulation of tumor cells endowed with tumor initiation and propagation ability and a physiopathological state leading to great resistance to conventional therapies. Because it was initially presumed that such cells originated from malignant transformation of normal stem cells and in view of their tumorigenic potential, these cells were designated as cancer stem (or stem-like) cells or tumor initiating/propagating cells. In this review they will be referred to as cancer stem cells (CSCs).

Isolation and subsequent studies of CSCs from different types of tumors pointed to these cells as major components of conventional treatment failure. As a consequence, targeting CSCs is a promising perspective for the development of novel more effective anticancer therapeutic protocols. In this context, great efforts are made to identify and develop new anti-CSC therapies. However, the more we learn about CSCs, the more it becomes obvious that targeting this particular cancer cell subpopulation will be challenging.

Cancer cells endowed with stem cell properties are maintained in vivo in a quiescent slow-growing state which preserves them from antiproliferating anticancer drugs. In addition, CSC function is elusive and may be enhanced or modified by environmental cues or treatment. Moreover, these modifications may occur in only a part of these cells leading to CSC heterogeneity within the same tumor. More importantly, normal or cancer cells without stem cell properties may be induced to treatment-resistant CSCs depending on signals from their microenvironment.

This review will describe CSCs' functional characteristics and some methods used for their identification. Relevant biological targets in CSCs will be presented with a focus on quiescence and plasticity, two major aspects of CSCs' physiopathology. Data presented aim to highlight future challenges in CSC targeting and elimination in order to eradicate tumors. 


\section{Malignancies with Hierarchical Organization and CSCs}

Evidence for the presence of cancer cells with stem cell properties in human malignancies was provided by Bonnet and Dick in the late nineties. These authors described CD $34^{+} / \mathrm{CD}_{3} 8^{-}$cancer cells able to initiate acute myeloid leukemia in immunocompromised mice. They postulated that these cells originate from oncogenic transformation of hematopoietic stem cells since they presented similarities in cell surface marker expression, proliferation, self-renewal, and differentiation abilities [1]. This discovery is at the basis of the hierarchical or cancer stem cell (CSC) model postulating that tumors are hierarchically organized with CSCs at the apex of this hierarchy. CSCs would be unique among cancer cells through their ability to sustain in vivo long-term tumorigenic potential [2]. It is of note that the CSC model does not imply that CSCs arise from oncogenic transformation of normal stem cells since any cell in the hierarchy with proliferative ability could be at the origin of CSCs and thus of tumors [3,4]. This hierarchical or CSC model was initially opposed to the clonal evolution theory suggesting that all undifferentiated cells within a tumor have equal tumorigenic potential provided by random additional mutations or epigenetic modifications [5]. Experimental data demonstrating that non-CSC populations may acquire CSC functionalities depending on the cell environmental context [6-8] supports the idea that the CSC and clonal evolution models present much more similarities than initially proposed.

Based on surface marker expression patterns, sphere formation ability, side population detection, and in vivo tumorigenic potential following serial transplantation [9], cancer stem cells have been subsequently isolated from numerous solid tumors, the first one being breast carcinoma [10, 11]. Additional solid tumors that adhere to the hierarchical or CSC model include, but are not limited to, brain [12-16], pancreatic $[17,18]$, colon [19-21], head and neck [22], hepatic [23], lung [24, 25], prostate [26], bladder [27], and ovarian malignancies [28, 29], as well as melanoma [30-32] and musculoskeletal sarcomas [33].

\section{CSC Properties. What Defines a CSC?}

Cell surface antigen expression profiles have been commonly used for enrichment of CSCs from tumors (Figure 1(a)). In acute myeloid leukemia, CSCs were shown to express CD34 (Cluster of Differentiation 34) and lack expression of CD38 [1, 34]. CD133 (prominin 1) expression was described and used for isolation of CSCs from various solid tumors including glioblastoma [15], prostate [26], colon [20, 21], lung [24], pancreatic [17], and ovarian cancers [35] and melanoma [36]. The CD44 adhesion molecule is another surface marker that has often been associated with CSC phenotypes. CSCs showing expressions of CD44 were described, for example, in breast [10], colorectal [19], pancreatic [18], and ovarian malignancies [29]. Several other surface markers have been used to define CSCs (reviewed in [37-39]). However, surface marker expression profiles may vary during tumor growth in vivo and as a function of experimental conditions in vitro. In addition, these markers often lack specificity and heterogeneity in marker expression may exist between patients and even within the same tumor [39]. Combining different markers was proposed to improve reliability of this type of approach. Alternatively, new, functional markers, most of which are associated with the intrinsic stem properties of CSCs, have been used. Increased ALDH1 (aldehyde dehydrogenase 1) expression was, for example, used as a marker of CSCs from mammary tumors [11] as well as of CSCs from bladder, lung, colon, esophageal, and head and neck squamous cell carcinomas [38]. Although not restricted to CSCs, expression of components of signaling pathways associated with cell pluripotency was also used to characterize these cells. Proteins whose expression was linked to the stem-like phenotype of CSCs include the OCT-4 (octamer-binding transcription factor 4), SOX2, and NANOG transcription factors (Figure 1(a)) as well as components of the Wnt $\beta$ catenin, Notch, and Hedgehog $(\mathrm{Hh})$ signaling modules [40, 41]. Reverse transcription followed by real-time polymerase chain reaction (PCR) is an extremely sensitive method commonly used for CSC marker identification. In this approach, expression levels of the gene(s) of interest need to be normalized against endogenous control genes (housekeeping genes) whose expression should be robust and highly stable in the experimental conditions used. In a recent study, the stability of 15 commonly used housekeeping genes was evaluated in CSC spheroids from musculoskeletal sarcomas and carcinomas and from breast and renal malignancies as well as in the corresponding adherent native tumor cell lines [42]. Housekeeping genes encoding Tata-Binding Protein (TBP), Tyrosine 3-monooxygenase/tryptophan 5-monooxygenase activation protein zeta polypeptide (YWHAZ), peptidylprolyl isomerase A (PPIA), hydroxymethylbilane synthase (HMBS), or GAPDH (glyceraldehyde-3-phosphate dehydrogenase), were shown to be appropriate for comparative expression studies in cells used in this report. In addition, the authors suggested that more than one endogenous control gene should be used for normalization and that different, specific housekeeping genes should be considered for distinct CSCs and/or as a function of experimental conditions [42]. Recent data obtained in our laboratory with human glioblastoma CSCs and control cells further argue in favor of the necessity to validate appropriate housekeeping genes for each experimental setting $[43,44]$.

Since marker expression is definitely not sufficient to define a specific CSC subpopulation, it is now a consensus that phenotypic characterization must be accompanied by functional validation of CSCs $[45,46]$. Thus, in addition to cell surface marker and stem cell marker expression profiling (Figure 1(a)) [9], various methods have been developed in vitro and in vivo to assess the stem cell properties of cells. Sphere formation assays following limiting dilution of cells are used for in vitro evaluation of cells' self-renewal and proliferation abilities (Figure 1(b)). Based on their increased efflux capacity of the Hoechst dye, mediated by overexpression of ATP-binding (ABC) cassette transporters, CSCs are designated as the side population (SP) cells (Figure 1(c)) [4749]. Differentiation potential is demonstrated by the ability 


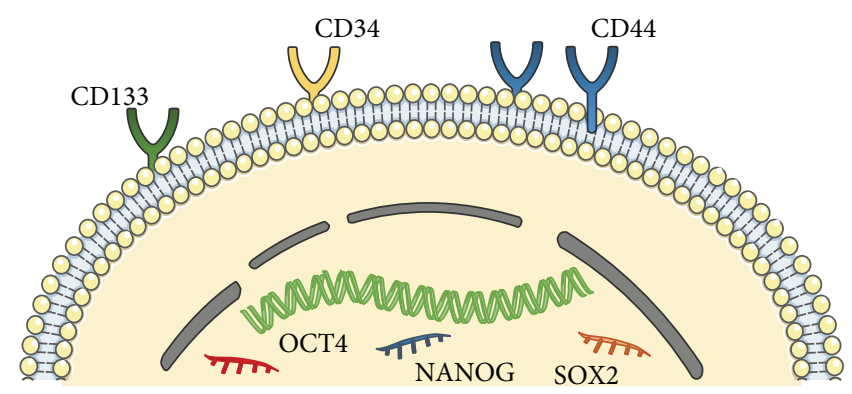

(a)

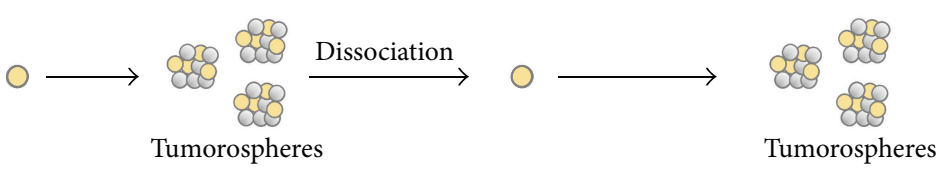

(b)

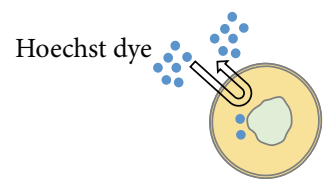

CSC side population (SP)
Hoechst dye $\therefore$

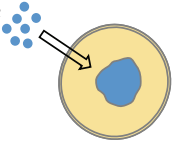

Non-CSC

(c)

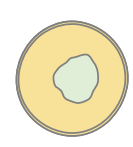

CSC $\overrightarrow{\text { Multilineage differentiation }}$

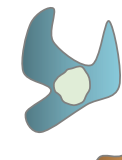

0

Differentiated cells

(d)

Xenograft of CSCs in limiting dilution

Serial transplantation of CSCs
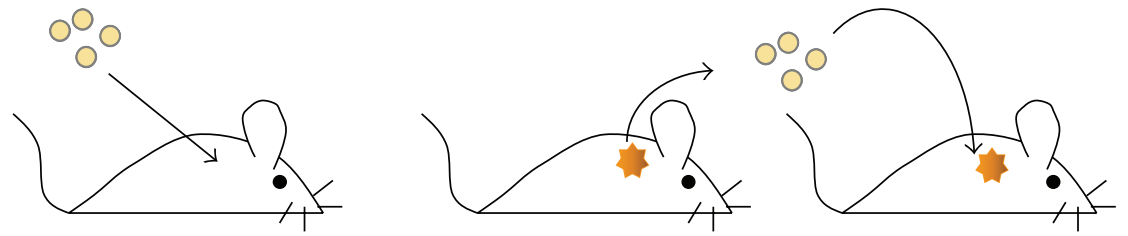

(e)

FIGURE 1: Cancer stem cell (CSC) properties and experimental methods for phenotypic and functional characterization of CSCs. (a) CSCs express cell surface antigens (CD133, CD34, and CD44) and signaling molecules (OCT4, NANOG, and SOX2) linked to a stem-like phenotype. CD: cluster of differentiation; OCT-4: octamer-binding transcription factor 4. (b) CSCs possess clonal properties and may be maintained in vitro for long intervals in serum-free medium. Under these conditions, they are able to form clonal tumorospheres. (c) CSCs present increased Hoechst efflux capacity compared to normal cells. Based on this property, they are designated as the side population (SP). (d) Multilineage differentiation (in the presence of serum) is another property of CSCs. Differentiation ability is verified by the decrease in the expression of stem cell markers accompanied by an increase in the expression of differentiation markers. Differentiated cells lose their tumorigenic potential. (e) CSCs at limiting dilutions are able to generate tumors after serial xenografting into immunocompromised mice. These tumors recapitulate the characteristics of the tumor from which CSCs were derived. Figure was constructed in part with objects from Servier Medical Art documents under license from Creative Commons Attribution 3.0 France (http://creativecommons.org/licenses/by/3.0/fr/legalcode).

of cells to undergo morphological changes when exposed to serum and by modifications in expression levels of stem cell and differentiation markers. In the differentiated state, cells lose their tumorigenic properties (Figure 1(d)). Finally, the gold standard for CSC validation is the in vivo ability of limiting dilutions of cells to recapitulate the heterogeneity and complexity of the initial tumor following serial orthotopic or ectopic transplantation in appropriate animal models (Figure 1(e)) $[9,38,50]$. Master and working cell banking of isolated CSCs, limited numbers of passages, and DNA fingerprinting are recommended to achieve nonderivation of CSCs from initial phenotypic and functional phenotypes in vitro. Several CSC properties and associated validation methods are shown in Figure 1.

\section{Well Established Biological Targets in CSCs Related to Treatment Resistance}

4.1. Self-Renewal Signaling Molecules. One of CSC's major features is their long-term self-renewal ability both in vitro and in vivo. Several pathways well known for their implication in embryonic development and differentiation and controlling stem cell self-renewal are preferentially activated in CSCs. These include the Wnt $/ \beta$-catenin, Notch, 
Hedgehog (Hh), and BMI1 pathways (Figure 2(a)) [51]. In addition, several studies suggest that EGF (epidermal growth factor), PI3K (phosphatidylinositol-3-phosphate kinase), MAPK (mitogen-activated protein kinase), and NF$\kappa \mathrm{B}-$ (nuclear factor kappa B-) mediated signaling is also involved in CSC self-renewal through cross-talk with the aforementioned pathways [52]. As a consequence, several strategies have been developed to target these pathways and a number of their inhibitors and/or regulators are under clinical investigation and some are already in clinical use $[51,53,54]$. However, various resistance mechanisms to these experimental drugs have been described. For example, resistance to inhibitors of Smoothened, a key molecule in the Hedgehog signaling pathway, has been attributed to activation of Smoothened downstream signaling partners by other signaling pathways [55]. Moreover, Smoothened mutations causing disruption of the inhibitor binding site were also described [56]. In addition to resistance mechanisms, some examples of absence of clinical efficacy have been reported $[54,57]$. These concerned trials without previous patient stratification for mutations in the targeted pathways. Absence of efficacy was also attributed to the fact that the CSC phenotype is not only the result of dysregulation of a single pathway but also the outcome of cross-talk between multiple signals. Thus, targeting one single pathway may not be sufficient [54].

4.2. Antiapoptotic Pathways. Overexpression of antiapoptotic molecules is another feature of CSCs (Figure 2(b)). For example, overexpression of genes encoding BCL2 and BCL$\mathrm{XL}$, which act as negative regulators of mitochondrial membrane permeabilization and cytochrome $C$ release [58], was reported in CSCs from high grade astrocytomas. In addition, higher levels of survivin, belonging to the IAP (inhibitors of apoptosis) family members and low mRNA levels of caspase 8 associated with TRAIL (tumor necrosis factor- (TNF-) related apoptosis-inducing ligand) resistance were described in other brain tumor-derived CSCs [59, 60]. Moreover, CSCs from glioblastoma, the most common and aggressive brain malignancy $[61,62]$, were less sensitive to BCL2 small molecule inhibitors compared to cancer cells without stem cell properties from the same tumor [63]. Interestingly, specific inhibition of antiapoptotic pathways was shown to reduce chemo- and radioresistance of glioblastoma CSCs and to specifically eliminate breast cancer stem cell activity $[64,65]$. However, presumably because of the coexistence of multiple antiapoptotic mechanisms, clinical trials based on the use of death receptor agonists were not conclusive. Association of these compounds with other antiapoptotic molecules such as BCL2 antagonists may be more relevant for efficient tumor targeting and elimination [53].

\subsection{Resistance to DNA Damage and Proteins Involved in DNA} Repair. Lesions induced by radiotherapy and chemotherapy with DNA damaging agents need to be repaired by the DNA damage response (DDR) pathways to allow cancer cells' survival following treatment. DDR mechanisms include both arrest of cells at specific checkpoints of the cell cycle and recruitment of the DNA repair machinery leading to elimination of lesions. Depending on the type of lesion, distinct sets of DNA repair proteins are involved [66].

In a pioneer study, Bao and coll. showed that $\mathrm{CD}_{133^{+}}$ glioblastoma CSCs contribute to radioresistance through preferential activation of the DNA damage checkpoint response (Figure 2(c)) involving the ataxia telangiectasia mutated (ATM) protein kinase and checkpoint kinase (Chk) 2 (Chk2). Interestingly, the radioresistance of these cells was reversed following specific inhibition of Chk1 and Chk2 [67]. Chk1 inhibitors were also able to sensitize pancreatic adenocarcinoma CSCs to gemcitabine, a cytidine analog used for the treatment of several malignancies including those of the pancreas [68].

In addition to activation of checkpoint responses, enhanced DNA repair mechanisms were reported for some types of CSCs (Figure 2(c)). Preferential activation of the DNA double strand break (DSB) repair response involving the polycomb group protein BMIl and the ATM protein kinase was observed in cancerous neural stem cells [69]. BMI1 deficiency resulted in increased sensitivity to radiation in both glioblastoma and head and neck squamous cell cancer-derived CSCs $[69,70]$. Preferential expression of other DNA repair-associated genes such as those encoding Methyl Guanine Methyl Transferase (MGMT) and BRCA1related DNA repair proteins was reported in CSCs from glioblastoma and pancreatic tumors, respectively [71, 72]. Moreover, enhanced Non-Homologous End Joining (NHEJ) activity and a more-rapid DNA repair were reported in CSCs from mammary tumors [73].

Finally, CSCs' chemo- or radioresistance was also associated with lower levels of reactive oxygen species (ROS) either because of lower ROS production rates or because of the presence of more efficient ROS scavenging systems in these cells involving multiple signaling pathways [74]. Interfering with CSCs' intracellular redox balance is thus an interesting approach for CSC elimination (Figure 2(c)) $[75,76]$.

4.4. Proteins Involved in Drug Efflux. One of the characteristics of CSCs is their increased efflux capacity of the Hoechst dye defining them as the side population (SP) cells (Figure 1(c)) [47-49]. This property has been used and is still applied for isolation of CSCs from a variety of tumors [77-79]. Increased expression of proteins belonging to the ATP-binding $(\mathrm{ABC})$ cassette transporter family is at the basis of this CSC property (Figure 2(d)) [80]. Among ABC transporters, P-glycoprotein (also known as multidrug resistance protein 1 (MDR1) or ABCB1), multidrug resistance associated proteins 1 and 2 (MRP1 or $\mathrm{ABCC1}$ and MRP2 or $\mathrm{ABCC} 2$ ), and breast cancer resistance protein (BCRP or ABCG2) are main actors of the multidrug resistance (MDR) phenotype which was also associated with CSC physiopathology [80]. Overexpression of ABC family members was described in glioblastoma, lung cancer, osteosarcoma, prostate and ovarian cancer, and nasopharyngeal carcinoma [80]. Three generations of ABC transporter blockers have been used. A fourth one based on natural compounds is under development [81, 82]. Inhibitors of the third generation which are less toxic and more specific, namely, the ones targeting BCRP, are under investigation in clinical trials 


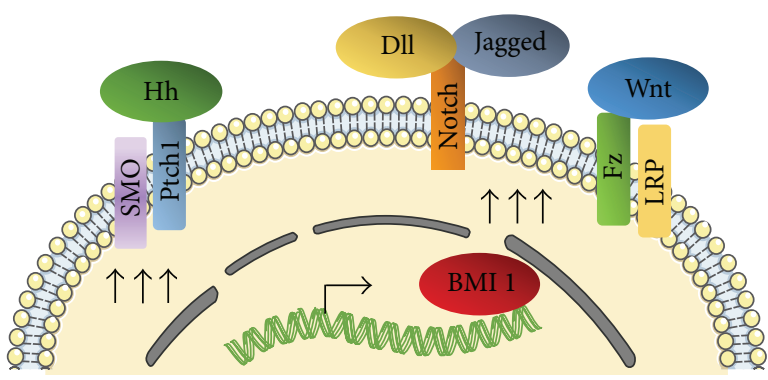

Increased self-renewal/survival signaling Self-renewal signaling molecules

(a)

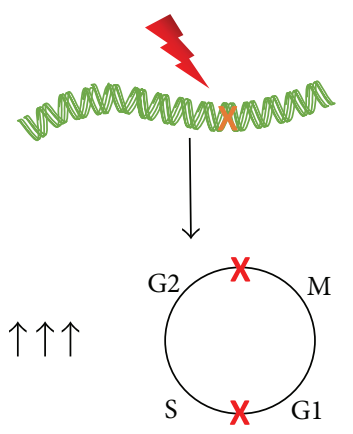

Longer checkpoint arrest Proteins involved in checkpoint arrest

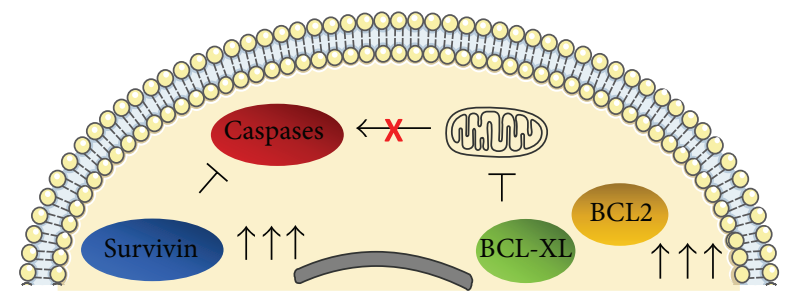

Increased antiapoptotic signaling Antiapoptotic molecules

(b)
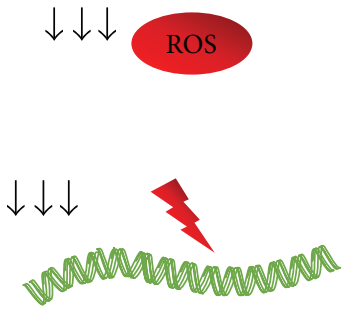

Less DNA damage

Proteins involved in intracellular redox balance

(c)

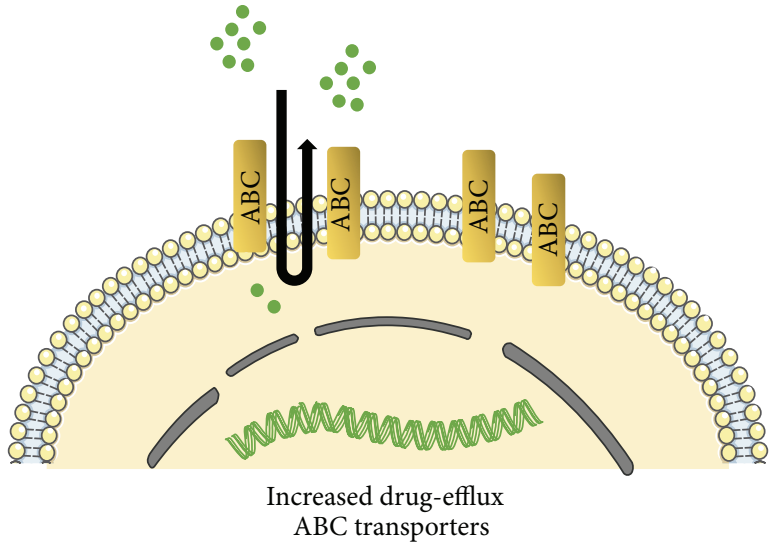

(d)

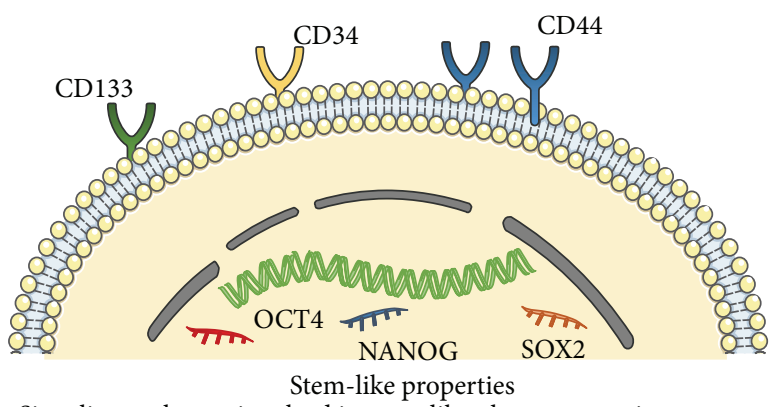

Signaling pathways involved in stem-like phenotype maintenance

(e)
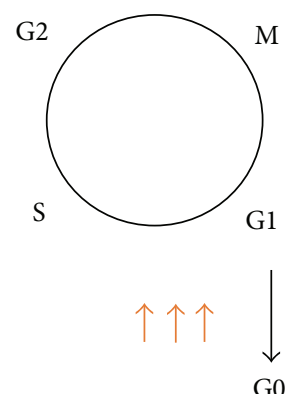

Quiescence

G0

Signaling pathways involved in stem-cell quiescence

(f)

Figure 2: Continued. 


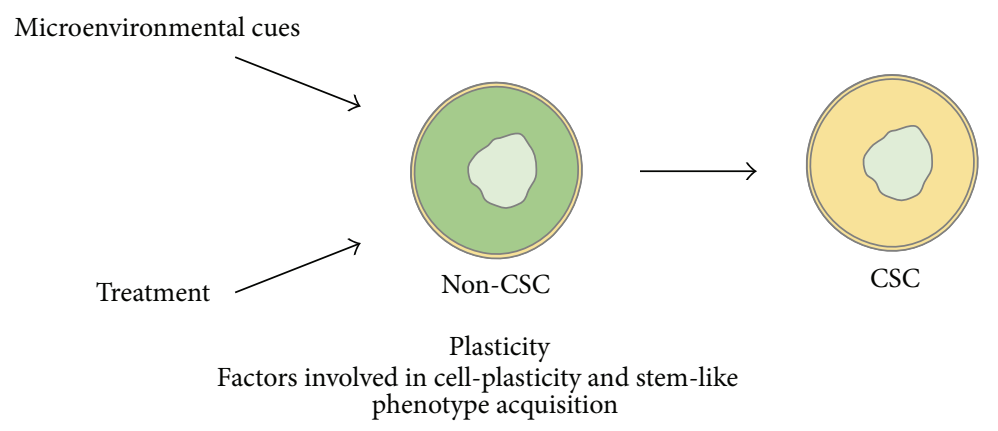

(g)

FIGURE 2: Mechanisms of CSCs' therapy resistance and relevant biological targets. ((a)-(b)) Increased self-renewal and prosurvival signaling have been reported for CSCs. Molecules involved in self-renewal/survival as well as antiapoptotic proteins overexpressed in CSCs are potentially interesting targets for therapies seeking CSC elimination. Hh: Hedgehog; SMO: Smoothened; Ptch1: Patched; Dll: Delta-like ligand; Wnt: wingless integration site; Fz: Frizzled; LRP: low-density lipoprotein receptor-related protein; BMI1: polycomb ring finger; BCLXL: B-cell lymphoma extra-large; BCL2: B-cell lymphoma 2. (c) CSCs respond with higher efficacy to DNA damage via checkpoint arrest for longer time intervals and enhanced DNA repair. Moreover, reduced levels of ROS have been reported in CSCs leading to protection of the CSC genome from DNA damage. Proteins involved in checkpoint arrest, DNA repair, and intracellular redox balance are relevant biological targets in CSCs. (d) Increased expression/function of ABC transporters in CSCs underlies more efficient drug efflux from these cells. ABC transporters are thus interesting therapeutic targets in CSCs. (e) Tumor initiation and propagation properties of CSCs involve their stem-like phenotype. Signaling modules involved in the maintenance of this state are relevant targets for CSC elimination. CD: cluster of differentiation; OCT-4: octamer-binding transcription factor 4. (f) Quiescent CSCs have been evidenced in many human malignancies and are major determinants of CSCs' resistance to current treatments. Neutralization of the CSC quiescent phenotype is a promising approach for new anticancer protocols. (g) Induced CSC-like phenotypes may be obtained by the action of signals from the tumor microenvironment and/or as a result of therapy. Cell plasticity observed in human malignancies must be taken into account when developing new anticancer therapies. Figure was constructed in part with objects from Servier Medical Art documents under license from Creative Commons Attribution 3.0 France (http://creativecommons.org/licenses/by/3.0/fr/legalcode).

whereas others are already used in clinic, for example, in colon carcinoma $[53,80]$.

4.5. Stem-Like Properties. Tumorigenic properties of CSCs and treatment resistance are closely linked to their undifferentiated phenotype and stem-like characteristics (Figure 2(e)). It was thus proposed that inducing CSC differentiation would be an efficient way to increase therapy efficacy. Differentiation therapy with various agents including all-trans retinoic acid and vitamin D3 has been proposed in the context of hematopoietic malignancies [83]. SAHA (suberoylanilide hydroxamic acid), a histone deacetylase (HDAC) inhibitor, was used to induce differentiation of various cancer cell types including those of breast and endometrial carcinomas [83]. CSCs isolated from glioblastoma and treated in vitro with bone morphogenetic protein 4 (BMP4) expressed higher levels of differentiation markers and lost their ability to generate glioblastoma-like lesions in xenografted mouse brains. These effects were dependent on Smad signaling [84]. However, some glioblastoma CSCs were subsequently shown to resist BMP4-induced differentiation because of epigenetic silencing of BMP receptors in these cells [85]. In a recent communication, Balasubramaniyan et al. reported that glioblastoma CSCs retained their selfrenewal and tumorigenic properties despite the induction of proneural differentiation factors by exposure to serum. Moreover, aberrant differentiation towards a mesenchymal phenotype was observed [86].

\section{Emerging Biological Targets and Treatment Resistance of CSCs}

5.1. Cell Quiescence. Cell quiescence may be defined as a reversible G0 phase from which cells may escape to reenter the cell cycle in response to physiological cell stimuli. It was suggested that cell quiescence is not just a passive state but rather a condition actively maintained and regulated by signaling pathways allowing rapid activation of quiescent cells and reentry in the cell cycle [87].

Signaling molecules participating in the regulation of stem cell quiescence include tumor suppressors p53 and RB (retinoblastoma protein), cyclin-dependent protein kinase inhibitors, namely, p21, p27, and p57, Notch-related pathways, and a number of miRNAs (micro-RNAs) [87]. Several transcription factors including FoxOs (Forkhead Box $\mathrm{O}$ ) and NFI (Nuclear Factor 1) protein member NFIX have also been involved in gene expression regulation in quiescent cells [88, 89].

Specific strategies allowing long-term survival through adaptive responses to environmental stress were reported for quiescent CSCs. For example, FoxO transcription factors, via PI3K-Akt-dependent pathways and regulation of ROS levels, were shown to participate in such adaptive mechanisms. Adaptive metabolic responses and mechanisms favoring maintenance of genomic integrity were also reported for these cells [87, 90, 91]. 
In cancer biology, tumor dormancy designates a frequent clinical phenomenon in which disseminated tumor cells are maintained in a nonproliferating quiescent state for long time intervals. This phenomenon may occur at early stages of the disease or following therapeutic intervention. Awakening of these dormant cells leads to tumor progression and relapse which may occur after very long periods [91, 92].

In addition to disseminated dormant tumor cells, CSCs with quiescent phenotypes also exist within tumors as suggested by in vitro and in vivo data. In 2009, based on the label retention properties of cells, Dembinski and Krauss identified a subpopulation of slow cycling cells in pancreas adenocarcinoma cell lines. Partial overlap between this subpopulation and stem cell marker expression was observed for some cancer cells. Interestingly, these cells survived following chemotherapy and exhibited increased tumorigenic and invasive potentials [93]. A label retention strategy was also used to identify, purify, and establish transcriptional signatures of quiescent normal mammary stem cells from cultured mammospheres. Transcriptional signatures of these cells allowed prospective identification of slowly dividing CSCs in breast tumors and highlighted the heterogeneity of such malignancies with respect to their CSC content [94]. In liver cancer, the cell surface marker CD13 was identified as a functional hallmark of potentially dormant CSCs. $\mathrm{CD}^{+} 3^{+}$cells retain dyes for long intervals, contain low levels of ROS, participate in chemoresistance, and present high tumorigenic potential in immunocompromised mice. In in vivo liver tumor models, combination of $\mathrm{CD} 13$ inhibition and 5 fluorouracil (5-FU) damaging cells in the $S$ phase of the cell cycle led to tumor volume reduction in a more effective way compared to either treatment alone [95]. JARID1B which is a histone 3 demethylase involved in transcriptional repression of Notch ligands was identified as a marker of temporarily distinct slow cycling melanoma cells. Targeting the slow cycling phenotype of these cells through JARID1B knockdown inhibited continuous growth and metastatic progression of melanomas in animal models [96]. Relatively quiescent CSCs were also isolated from ovarian cancer patient specimens [97] as well as from the colo205 human colon adenocarcinoma cell line [98]. Label retaining glioblastoma CSCs generating tumors which present all the pathological features of the primary disease were first described by Deleyrolle et al. [99]. Endogenous glioblastoma CSCs, expressing a transgene that labels quiescent adult neural stem cells of the subventricular zone and staining negative for proliferation marker Ki-67 expression, were subsequently identified by Chen et al. in a genetically engineered mouse model of glioma. Following treatment with temozolomide (TMZ), one of the standards of care for glioblastoma together with surgery and radiotherapy, this cancer cell subpopulation was able to drive tumor regrowth through the production of highly dividing cells. Interestingly, ablation of this particular cancer cell subpopulation hindered tumor development [100]. In another study, Patel et al. used RNA seq-based single cell transcriptomic analysis to demonstrate that glioblastomas are highly heterogeneous tumors harboring variable proportions of cells expressing markers that have previously been associated with quiescence. These cells are also characterized by the presence of a stemness signature which is attributed to glioblastoma CSCs [101]. Finally, HIF1 $\alpha$ - (hypoxia-inducible factor 1 alpha-) positive quiescent glioblastoma cells with stem properties were localized by immunocytochemicalbased methods in perinecrotic niches in glioblastoma patient specimens. Suppressed phosphorylation of serine 2 in the CTD (C terminal domain) of RNA polymerase II, previously observed in various types of quiescent noncancerous stem cells, was used as an indicator of quiescence in their report [102].

The quiescent state of CSCs protects these cells from antiproliferating agents and is thus an important factor of CSC-related resistance to conventional therapy (Figure 2(f)). Three major strategies have been reported for targeting this particular slow cycling CSC subpopulation (Figure 3). The first one consists in forcing CSCs to reenter the cell cycle and was designated as the "locked-out" situation. This was suggested to be of benefit for cancer treatment since a majority of chemotherapeutic agents including mitotic inhibitors, antimetabolite drugs, and topoisomerase inhibitors may only exhibit cancer cell cytotoxicity on proliferating cells. For example, ablation of the F-box protein Fbxw7 leads to a decrease in ubiquitin-dependent degradation of c-Myc, Notch, and cyclin E and reentry in the cell cycle and increases the sensitivity of Phi + leukemia CSCs to imatinib [103]. Leukemia CSCs were also sensitized to cell cycle dependent chemotherapy after treatment with mitogens (GCSF) [104]. However, the "locked-out" approach might be risky in case all awakened cancer cells are not efficiently eliminated by available antiproliferating agents since this would lead to disease progression. Moreover, exit from dormancy of heterogeneous populations of cancer cells may increase the genetic and epigenetic complexity of the tumor and allow more efficient resistance to treatment [92]. To overcome these limitations, some authors have proposed alternative targeting strategies. One of them is the "locked-in" strategy in which pharmacological maintenance of CSCs in the G0 phase aims to prevent further tumor growth, relapse, and/or metastasis throughout the lifetime of a patient. Eradicating CSCs while they are dormant is another alternative to dormant cancer cell awakening.

Deeper understanding of signaling pathways and factors involved in cell quiescence is a prerequisite to the success of those latter strategies. For example, reduced PI3KAKt signaling was associated with dormant phenotypes. In addition, inhibition of mitogenic signals was shown to trigger quiescence. Combining cell survival blockers, that is, ABT-737, a BCL2, and BCL-XL inhibitor to EGFR (Epidermal Growth Factor Receptor) inhibition by erlotinib, was able to lead to elimination of erlotinib-induced quiescent cells in non-small-cell lung cancer xenografts. Alternatively, the quiescent state may be actively induced by specific kinases including DYRK1B (dual specificity tyrosine phosphorylation-regulated kinase $1 \mathrm{~B}$ ). This kinase was shown to block proteins involved in the G0/G1/S transition. DYRK1A, a DYRK1B related kinase, can also induce quiescence together with coordinating survival via an antioxidant response. Inhibition of DYRK1A leads to cytotoxicity towards quiescent pancreatic cancer cells while preserving normal 


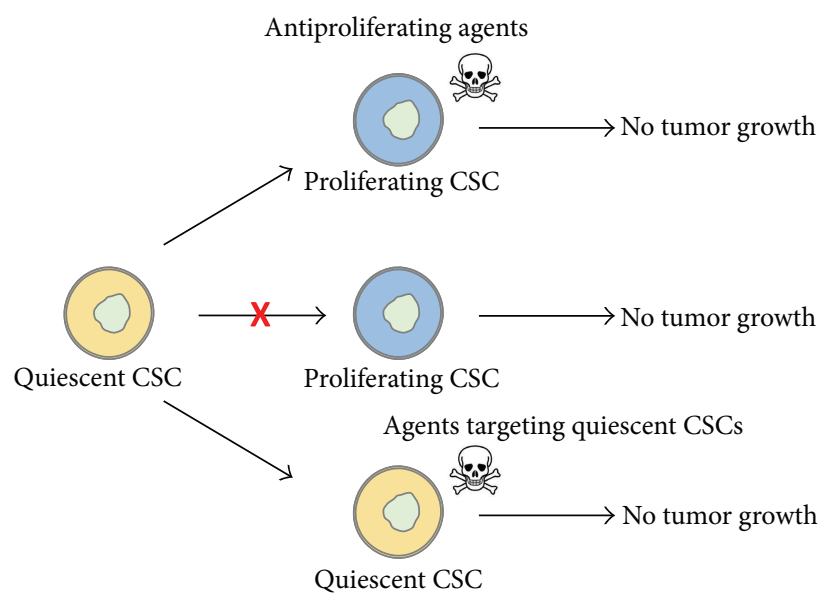

FIGURE 3: Strategies proposed for neutralization of the CSC quiescent phenotype involved in treatment resistance. Three strategies have been proposed to neutralize the quiescent CSC-state. Induction of CSC entry into the cell cycle would sensitize cells to antiproliferating agents. Blocking quiescent CSCs in G0 was proposed as an alternative for preventing new tumor growth. Targeting CSCs in the quiescent state was also proposed for the elimination of this particular CSC subpopulation. CSC: cancer stem cell. Figure was constructed in part with objects from Servier Medical Art documents under license from Creative Commons Attribution 3.0 France (http://creativecommons.org/licenses/by/3.0/fr/legalcode).

quiescent cells. The underlying mechanisms are not known [92]. The p38 MAPK (Mitogen-Activated Protein Kinase) along with TGF $\beta$ (Transforming Growth Factor beta)/BMP (Bone Morphogenetic Protein) signaling were also involved in the maintenance and/or induction of the quiescent state [105-107]. The DNA methylation inhibitor 5-azacytidine was shown to cause a decrease in expression of genes involved in exit from the G0 phase and entry in G1 in primary cells and in leukemia and breast cancer cell lines and upregulation of genes involved in a p38-related dormancy signature [105]. The same authors reported that combinations of 5-azacytidine and all-trans retinoic acid induce a stable quiescent state which may be maintained for a long period of time [92]. We have recently developed an in vitro model of reversibly quiescent glioblastoma CSCs based on the maintenance of patient derived CSCs without medium renewal for several days. These cells were shown to present decreased EdU (5ethynyl-2' -deoxyuridine) incorporation rates and very low levels of Ki-67 expression. No significant increase in the expression of apoptotic markers was observed in these conditions. We additionally showed that quiescent glioblastoma CSCs showed similar expression of surface markers and comparable in vitro sphere forming and differentiation abilities, when returned to proliferation or differentiation-promoting culture conditions, as their proliferating counterparts. Moreover, in vivo engraftment capacity was maintained. Screening of the Prestwick Chemical library, mainly composed of FDA-approved drugs currently used in various therapeutic domains, on proliferating and quiescent glioblastoma CSCs, led to the identification of the stimulant laxative bisacodyl as a potent and specific inhibitor of quiescent glioblastoma CSC survival, with an IC50 value around $1 \mu \mathrm{M}$. Bisacodyl was ineffective on proliferating CSCs from the same patient, as well as on normal fetal neural stem cells and primary astrocytes [44]. To our knowledge, no other small molecules with similar activity profiles have been reported so far. The molecular mechanisms underlying bisacodyl's activity on quiescent glioblastoma CSCs are currently under investigation in our laboratory.

5.2. CSC Plasticity. Initially, CSCs were considered as a static well-defined subpopulation of cancer cells with invariable functional characteristics distinguishing them from cells of the tumor mass. Nowadays, the CSC phenotype is considered as a transient state that any cell may acquire depending on cues provided by its microenvironment (Figure 2(g)) [108]. Epigenetic modifications are a major source of this kind of cell plasticity. Genomic alterations and selection of mutant cells may also participate in this phenomenon $[109,110]$.

Cell plasticity with acquisition of stem-like properties was described in several cancers. In melanoma, it was shown that many phenotypically distinct types of cancer cells with respect to surface marker expression were able to form tumors that recapitulate the characteristics of the original malignancy. This suggested that tumorigenic cells may undergo reversible phenotypical changes in vivo [111]. In addition, Roesch and colleges described a slow cycling melanoma CSC subpopulation whose existence within the tumor bulk was regulated over time as evidenced by marker expression modifications [96]. In another study, genetically engineered transformed mammary epithelial cells were shown to spontaneously generate cancer stem-like cells both in vitro and in vivo [6]. The same authors subsequently showed that switching of human basal breast cancer cells from a non-CSC to a CSC-state may be achieved through mesenchymal phenotype-inducing signals [7]. More recently, reprogramming of the tumor propagating potential of differentiated glioblastoma cells was achieved through expression of a set of transcription factors involved in neuronal development, namely, POU3F2, SOX2, SALL2, and OLIG2 [112]. 


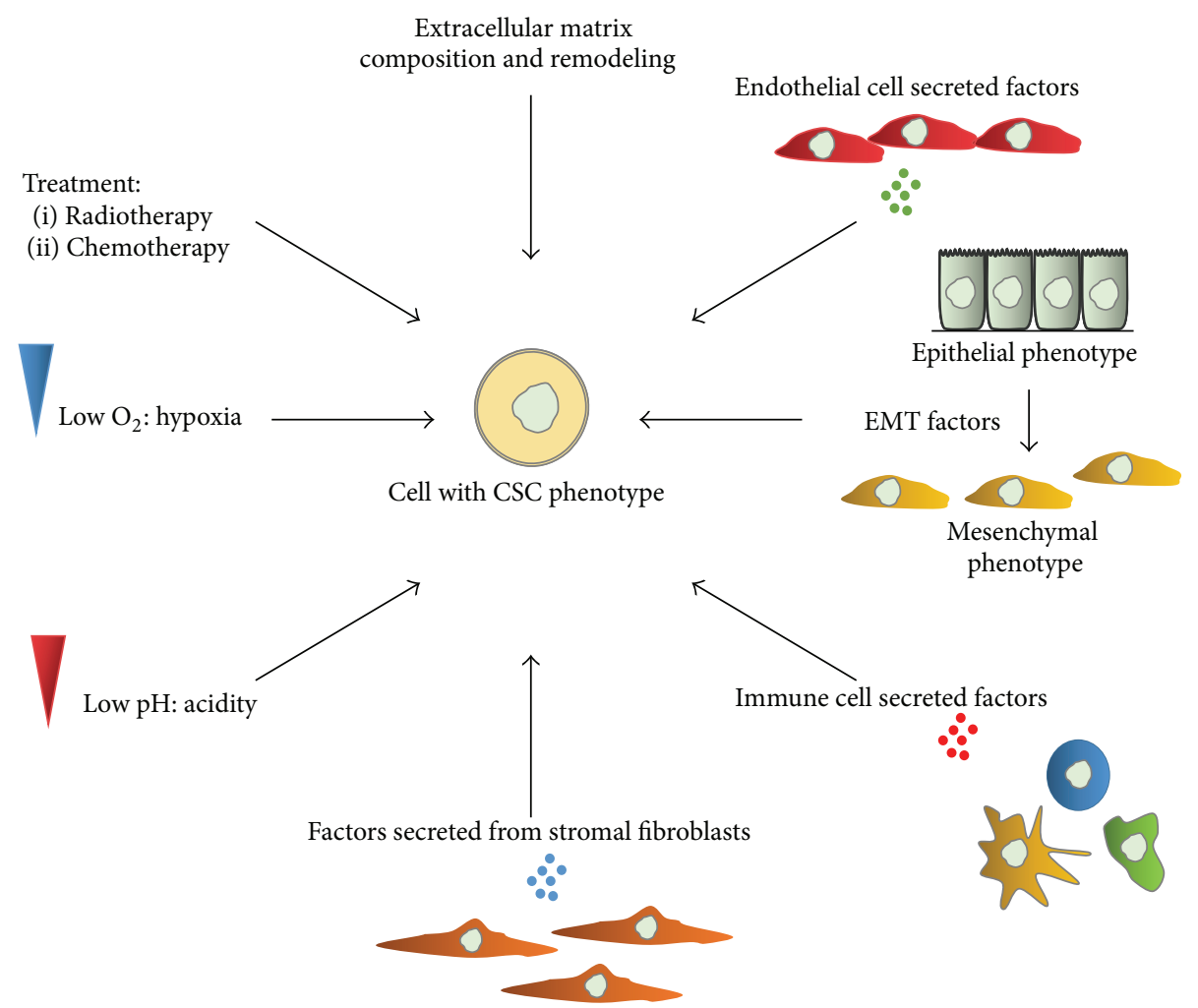

Figure 4: Mechanisms inducing CSC phenotypes. The CSC phenotype of cancer cells is influenced by cues related to the tumor microenvironment. These include remodeling of the extracellular matrix and signaling through factors secreted by endothelial, immune system cells and stromal fibroblasts. Signaling related to EMT (epithelial to mesenchymal transition) may also induce a CSC phenotype. Low oxygen (hypoxia) and acidic conditions nearby the CSC niche may induce and/or enhance the CSC phenotype of cells. Radiotherapy and chemotherapy have been shown to induce dedifferentiation of cancer cells and acquisition of a CSC phenotype. Figure was constructed in part with objects from Servier Medical Art documents under license from Creative Commons Attribution 3.0 France (http://creativecommons.org/licenses/by/3.0/fr/legalcode).

Induced CSCs were also obtained from colon cancer cells through introduction of three factors, OCT3/4, SOX2, and KLF4 [113].

Cancer cell plasticity with respect to the acquisition or loss of stem-like properties may be induced by either microenvironmental-/niche-derived signaling cues and/or as a result of antitumor therapeutic intervention (Figure 4). Tumors may be considered as organ-like structures in which cancer cell function is supported/regulated by matrix remodeling, blood vessel development, cancer associated fibroblast function, and recruitment of immune cells [114, 115]. Each of these factors may contribute to the functional properties of cancer cells and affect cell response to chemo- and radiotherapy by protecting cells from these agents [108]. It is important to note that vascular supply, access to growth factors, structural support, and interactions with immune cells vary within a single tumor. In other words, all cancer cells do not share the same microenvironmental conditions or the same niche [114]. Some authors suggested that within tumors, CSCs reside in particular niches whose function is to preserve their functional properties and plasticity and facilitate their metastatic potential [116]. In addition, it was proposed that CSC niches may be modified as a function of tumor stage or nature (initial or metastatic) [117].
Microenvironmental signals that can regulate cancer stem cell fate and metastatic potential include reorganizations of the extracellular matrix, autocrine and paracrine factors, low oxygen (hypoxia), and/or nutrient supply and signals derived from immune cells.

Extracellular matrix composition and remodeling have been associated with many aspects of cancer physiopathology as well as in the regulation of stem cell fate [118-120]. In a recent study, extracellular matrix small leucine-rich proteoglycans (SLRPs) decorin and lumican were shown to be expressed at higher levels in glioblastoma and neuroblastoma cancer cells induced in vitro to a more stem-like phenotype. Resulting cells forming neurospheres had a slow cycling phenotype and were more resistant to treatment [121].

A role of tumor microvascular endothelial cell-secreted factors on the induction of a stem cell phenotype in differentiated glioblastoma cells was also established. The authors showed that basic fibroblast growth factor (bFGF) secreted by endothelial cells induces increased stem cell marker expression and sphere forming ability of differentiated glioblastoma cells [122].

Epithelial to mesenchymal transition (EMT) is a process initially described in embryogenesis. During this process, differentiated polarized epithelial cells acquire a mesenchymal 
phenotype and a more motile and invasive behavior [123, 124]. EMT is induced by environmental cues including TGF $\beta$ and receptor tyrosine kinase ligands and is accompanied by complex gene expression modifications [123]. In the context of cancer, EMT was initially described as a mechanism presumably providing cancer cells with invasive and metastatic properties. More recently, similarities between EMT-induced properties and CSC functional characteristics were highlighted and EMT following tumor microenvironmental cues was proposed to result in acquisition of CSC-like phenotypes by cancer cells $[123,125]$. For example, it was shown that transformed human mammary epithelial cells acquire CSC properties after undergoing EMT $[126,127]$. EMT in this case may be triggered by expression of particular transcription factors, cytokines including TGF $\beta$, or following an immune response. In addition, in some cases, a stem-like phenotype has been reported for metastatic cancer cells which have presumably undergone EMT $[123,125]$. Moreover, exposure of lung cancer cells to TGF $\beta 1$ resulted in the switching of some cells to a stem-like phenotype [128].

Immune cells of the tumor microenvironment were also shown to secrete factors that are able to interfere with the stem cell properties of cancer cells. IL- (interleukin-) 22 secreted by $\mathrm{T}$ cells is able to modulate STAT3 signaling in cancer cells and expression of stem cell-associated genes like those encoding NANOG, SOX2, and POU5F1. This leads to increased tumorigenic potential of colorectal cancer cells [129]. Proinflammatory factors such as tumor necrosis factor alpha (TNF $\alpha)$ and IL-6, secreted by immune cells in the tumor microenvironment, are able to modify the differentiation state of cancer cells through upregulation of the expression of mesenchymal phenotype-associated genes. This type of stem-like phenotype regulation was described for melanomas and breast and lung cancers. In colon cancer, NF$\kappa \mathrm{B}$ and Wnt activation was linked to dedifferentiation of cells lacking stem-like properties [108] whereas in breast cancer, $\mathrm{T}$ cells were shown to promote EMT and acquisition of CSC functions [130].

Interactions between other types of stromal cells and cancer cells were reported in various malignancies including pancreatic, breast, and colon cancer. In pancreatic cancer models, factors secreted from stellate cells (myofibroblasts) induce expression of stem-like or mesenchymal-like fate associated genes and favor CSC phenotypes [131, 132]. In colon cancer, hepatocyte growth factor secreted by myofibroblasts was shown to restore a CSC-like phenotype both in vitro and in vivo through regulation of the Wnt pathway $[133,134]$.

One of the hallmarks of solid tumors is the presence of hypoxic regions containing reduced oxygen levels $(<2 \%)$. Hypoxic zones result from high oxygen demand of cancer cells and low oxygen supply due to irregularities in tumor vascularization or distance from supporting blood vessels [135]. Hypoxia-inducible factors (HIFs) are a family of transcription factors functioning as heterodimers in which one of several $\alpha$ subunits (HIF1 $\alpha, \mathrm{HIF} 2 \alpha$, and $\mathrm{HIF} 3 \alpha$ ) is associated with a $\beta$ subunit (HIF1 $\beta$ ). HIF proteins act as major sensors of low oxygen levels. Stabilization of HIF proteins leads to the regulation of the expression of numerous genes involved in
$\mathrm{pH}$ homeostasis, epigenetic regulation, extracellular matrix remodeling, proliferation, migration, survival, angiogenesis, and cell metabolism regulation by increasing glycolysis and decreasing mitochondrial function [136-138]. Hypoxic conditions were linked to promotion of stem-like properties as well as to EMT [138-140]. Increased expression of stem cell markers was observed in cancer cell lines from prostate, brain, kidney, cervix, lung, colon, liver, and breast tumors subjected to hypoxic conditions. These events were linked to HIF protein stabilization and function [141]. In addition, HIF proteins, and more particularly HIF $2 \alpha$, were shown to regulate glioblastoma stem cell properties including sphere formation and tumorigenic potential [142, 143]. Several examples of hypoxia-induced promotion of a dedifferentiated phenotype were reported in breast carcinomas [144, 145]. Moreover, high numbers of tumorigenic cells were localized in hypoxic regions of neuroblastomas [146] and upregulation of CD133, a surface marker linked to CSCs, was reported in medulloblastoma cells under hypoxia [147].

Hypoxia was also linked to the induction of EMT via HIFdependent or independent mechanisms [148-150]. Increased expression of EMT- and stem cell-related markers was observed in gastric cancer cells cultivated in hypoxic conditions. These cells had higher proliferation and migration rates and were more invasive. Increased ability to form colonies in soft agar was also reported for these cells [151]. In melanoma cells, hypoxic conditions lead to HIF-dependent Snaill overexpression, decreased E-cadherin levels, and acquisition of melanoma CSC features [152].

One of the functional consequences of low oxygen availability in some regions of a tumor and HIF stabilization is the induction of glycolytic enzymes and a shift from oxidative phosphorylation to glycolysis for energy production. This leads to increased production of metabolic acids such as lactic acid and acidification of the cells' extracellular environment [153]. Acidic stress was also shown to promote CSC-like phenotypes. When CSCs from glioblastoma or CSC-depleted cultures of glioblastoma cells were exposed to low $\mathrm{pH}$, an increase in the expression of CSC markers including OLIG2, OCT4, and NANOG was observed. In addition, cells acquired greater neurosphere formation capacity in vitro as well as increased tumorigenicity in vivo [154].

Cancer cell plasticity and generation of CSCs from nonCSC-like cancer cells have been frequently reported as a consequence of treatment. Ionizing radiation-reprogrammed breast cancer cells lacking stem cell properties into induced breast CSCs expressing the same markers as their nonirradiated counterparts and possessing increased mammosphereformation ability and tumorigenic potential [155]. In head and neck squamous cell carcinomas, cisplatin was shown to promote survival and self-renewal of CSCs in vitro through increased expression of BMI1 [156]. Melanoma treatment with cisplatin and vemurafenib led to the enrichment of slow cycling cells which are able to sustain long-term tumor growth [157]. Colon cancer cells obtained following 5-FU (5-fluorouracil) treatment present mesenchymal stem-like properties, express stemness markers, and possess spherogenic potential [158]. Finally, several reports have linked chemotherapy to transition into a stem-like phenotype 
associated with EMT. Some of these reports have been reviewed in $[110,125]$.

5.3. CSC Metastatic Potential. To form metastasis, primary tumor cells need to escape the physical barriers at the primary tumor site, enter the vascular system, infiltrate distant organs, survive, and proliferate at these secondary sites [159]. Because of all these bottlenecks, the metastatic process is rather inefficient and not all primary tumor cells possess metastatic potential. Metastatic potential of tumor cells is dependent both on their origin or their level of differentiation and on the occurrence of genetic and epigenetic changes linked to gene expression modifications that may act as cell fate determinants [160]. For example, in breast cancer, genes and signals involved in metastasis initiation and progression have been described. These include the TWIST1 gene implicated in EMT, matrix metalloproteinase encoding genes involved in extracellular matrix degradation, genes playing a role in extravasation, in activation of prosurvival and self-renewal signaling pathways, and in initiation of tumor growth at the secondary site [161]. Some metastatic cues may act in a tissue-specific manner, thus directing primary tumor cell initiation of metastatic lesions to specific target organs. The ones driving organ-specific breast cancer metastasis have been reviewed in [161]. Because of their increased prosurvival and self-renewal ability and their tumor initiation properties, CSCs are attractive candidates as tumor cells participating in the metastatic process. Moreover, CSCs have been extensively linked to EMT $[123,125]$ and subsets of circulating tumor cells with metastatic initiation ability were shown to express high levels of stem cell markers [162-164]. Recently, human metastatic breast cancer cells were shown to possess a stemlike gene expression signature [165]. In addition, loss of differentiation-inducing factors or acquisition of stem cell signaling was related to the development of metastases [160] and CSCs were shown to participate in metastatic colonization by regulating components of their niche at secondary target organs [166]. Metastatic relapse is a major cause of cancer treatment failure. The lack of efficacy of current treatments against metastatic disease was attributed to the presence of genetic alterations in metastatic cells that differ from the ones that are present in primary tumor cells, to the clinical dormancy phenotype of metastatic cells before reamplification at the secondary site as well as to drug resistance induced by treatment. The involvement of treatment-resistant CSCs in this process is also contributing to this phenomenon [160].

\section{Concluding Remarks}

In the past years CSCs have been a topic of intense investigation. As a result, the literature referring to this particular cancer cell subpopulation is very rich and sometimes contradictory. Nowadays, researchers in the field agree that CSCs represent a population of cancer cells with specific properties which definitely distinguish them from cells of the tumor bulk. CSCs are thought to possess or to be able to acquire properties allowing them to resist conventional treatments with great efficacy. Several aspects underlying
CSCs' resistance to treatment have been discussed in this review. Because of their resistant phenotype, CSCs have a major implication in tumor relapse following treatment. This has been established for numerous types of malignancies. Thus, new therapies need to target both CSCs and more differentiated cancer cells to be efficient. Intense fundamental and clinical research is developing in this field.

The increasing amount of knowledge concerning signaling pathways and cell mechanisms used by CSCs to sustain their physiopathological functions and induce their resistance to treatment is put to profit for the identification of novel pertinent CSC-targeting strategies. Efforts to target CSCs are however complicated by the probable presence, in vivo, of CSCs with a slow-growing status. Such cells will greatly resist antiproliferating molecules disclosed through screening approaches on proliferating CSCs maintained and studied in vitro. In the future, development of experimental models of quiescent CSCs will be a prerequisite to understanding specific characteristics of these cells and identifying potentially successful strategies to specifically eliminate the slow-growing CSC subpopulation.

Another critical point is the elusive nature of CSCs. Within a tumor, cells may acquire, enhance, or lose CSC functionalities depending on their microenvironment and challenging by treatment. This implies that any cell within a tumor may become resistant to treatment and that heterogeneity in CSC content and nature may occur within the same tumor or between tumors in distinct patients. CSCs are thus moving targets and their elusive nature needs to be taken into account in future anticancer therapy developments. Combinations of treatments and continuous adaptability to patients' response may be part of the answer.

\section{Competing Interests}

The authors declare that there is no conflict of interests regarding the publication of this paper.

\section{Acknowledgments}

The authors thank "La Ligue contre le Cancer" for Ph.D. funding of Wanyin Chen as well as for additional financial support, the Strasbourg University, and the CNRS (Centre National de la Recherche Scientifique). Their projects are developed within the LABEX ANR-10-LABX-0034_Medalis and received a financial support from French government managed by "Agence Nationale de la Recherche" under "Programme d'Investissement d'Avenir."

\section{References}

[1] D. Bonnet and J. E. Dick, "Human acute myeloid leukemia is organized as a hierarchy that originates from a primitive hematopoietic cell," Nature Medicine, vol. 3, no. 7, pp. 730-737, 1997.

[2] M. Shackleton, E. Quintana, E. R. Fearon, and S. J. Morrison, "Heterogeneity in cancer: cancer stem cells versus clonal evolution," Cell, vol. 138, no. 5, pp. 822-829, 2009. 
[3] F. Islam, B. Qiao, R. A. Smith, V. Gopalan, and A. K.-Y. Lam, "Cancer stem cell: fundamental experimental pathological concepts and updates," Experimental and Molecular Pathology, vol. 98, no. 2, pp. 184-191, 2015.

[4] J. E. Visvader, "Cells of origin in cancer," Nature, vol. 469, no. 7330, pp. 314-322, 2011.

[5] J. E. Visvader and G. J. Lindeman, "Cancer stem cells in solid tumours: accumulating evidence and unresolved questions," Nature Reviews Cancer, vol. 8, no. 10, pp. 755-768, 2008.

[6] C. L. Chaffer, I. Brueckmann, C. Scheel et al., "Normal and neoplastic nonstem cells can spontaneously convert to a stemlike state," Proceedings of the National Academy of Sciences of the United States of America, vol. 108, no. 19, pp. 7950-7955, 2011.

[7] C. L. Chaffer, N. D. Marjanovic, T. Lee et al., "XPoised chromatin at the ZEB1 promoter enables breast cancer cell plasticity and enhances tumorigenicity," Cell, vol. 154, no. 1, pp. X61-74, 2013.

[8] D. Iliopoulos, H. A. Hirsch, G. Wang, and K. Struhl, "Inducible formation of breast cancer stem cells and their dynamic equilibrium with non-stem cancer cells via IL6 secretion," Proceedings of the National Academy of Sciences of the United States of America, vol. 108, no. 4, pp. 1397-1402, 2011.

[9] L. Fulawka, P. Donizy, and A. Halon, "Cancer stem cells-the current status of an old concept: literature review and clinical approaches," Biological Research, vol. 47, no. 1, article 66, 2014.

[10] M. Al-Hajj, M. S. Wicha, A. Benito-Hernandez, S. J. Morrison, and M. F. Clarke, "Prospective identification of tumorigenic breast cancer cells," Proceedings of the National Academy of Sciences of the United States of America, vol. 100, no. 7, pp. 39833988, 2003.

[11] C. Ginestier, M. H. Hur, E. Charafe-Jauffret et al., "ALDH1 is a marker of normal and malignant human mammary stem cells and a predictor of poor clinical outcome," Cell Stem Cell, vol. 1, no. 5, pp. 555-567, 2007.

[12] R. Galli, E. Binda, U. Orfanelli et al., "Isolation and characterization of tumorigenic, stem-like neural precursors from human glioblastoma," Cancer Research, vol. 64, no. 19, pp. 7011-7021, 2004.

[13] H. D. Hemmati, I. Nakano, J. A. Lazareff et al., "Cancerous stem cells can arise from pediatric brain tumors," Proceedings of the National Academy of Sciences of the United States of America, vol. 100, no. 25, pp. 15178-15183, 2003.

[14] S. K. Singh, I. D. Clarke, M. Terasaki et al., "Identification of a cancer stem cell in human brain tumors," Cancer Research, vol. 63, no. 18, pp. 5821-5828, 2003.

[15] S. K. Singh, C. Hawkins, I. D. Clarke et al., "Identification of human brain tumour initiating cells," Nature, vol. 432, no. 7015, pp. 396-401, 2004.

[16] X. Yuan, J. Curtin, Y. Xiong et al., "Isolation of cancer stem cells from adult glioblastoma multiforme," Oncogene, vol. 23, no. 58, pp. 9392-9400, 2004.

[17] P. C. Hermann, S. L. Huber, T. Herrler et al., "Distinct populations of cancer stem cells determine tumor growth and metastatic activity in human pancreatic cancer," Cell Stem Cell, vol. 1, no. 3, pp. 313-323, 2007.

[18] C. Li, D. G. Heidt, P. Dalerba et al., "Identification of pancreatic cancer stem cells," Cancer Research, vol. 67, no. 3, pp. 1030-1037, 2007.

[19] P. Dalerba, S. J. Dylla, I.-K. Park et al., "Phenotypic characterization of human colorectal cancer stem cells," Proceedings of the National Academy of Sciences of the United States of America, vol. 104, no. 24, pp. 10158-10163, 2007.
[20] C. A. O’Brien, A. Pollett, S. Gallinger, and J. E. Dick, “A human colon cancer cell capable of initiating tumour growth in immunodeficient mice," Nature, vol. 445, no. 7123, pp. 106-110, 2007.

[21] L. Ricci-Vitiani, D. G. Lombardi, E. Pilozzi et al., "Identification and expansion of human colon-cancer-initiating cells," Nature, vol. 445, no. 7123, pp. 111-115, 2007.

[22] M. E. Prince, R. Sivanandan, A. Kaczorowski et al., "Identification of a subpopulation of cells with cancer stem cell properties in head and neck squamous cell carcinoma," Proceedings of the National Academy of Sciences of the United States of America, vol. 104, no. 3, pp. 973-978, 2007.

[23] Z. F. Yang, D. W. Ho, M. N. Ng et al., "Significance of CD90+ cancer stem cells in human liver cancer," Cancer Cell, vol. 13, no. 2, pp. 153-166, 2008.

[24] A. Eramo, F. Lotti, G. Sette et al., "Identification and expansion of the tumorigenic lung cancer stem cell population," Cell Death and Differentiation, vol. 15, no. 3, pp. 504-514, 2008.

[25] C. F. Bender Kim, E. L. Jackson, A. E. Woolfenden et al., "Identification of bronchioalveolar stem cells in normal lung and lung cancer," Cell, vol. 121, no. 6, pp. 823-835, 2005.

[26] A. T. Collins, P. A. Berry, C. Hyde, M. J. Stower, and N. J. Maitland, "Prospective identification of tumorigenic prostate cancer stem cells," Cancer Research, vol. 65, no. 23, pp. 1094610951, 2005.

[27] K. S. Chan, I. Espinosa, M. Chao et al., "Identification, molecular characterization, clinical prognosis, and therapeutic targeting of human bladder tumor-initiating cells," Proceedings of the National Academy of Sciences of the United States of America, vol. 106, no. 33, pp. 14016-14021, 2009.

[28] P. P. Szotek, R. Pieretti-Vanmarcke, P. T. Masiakos et al., "Ovarian cancer side population defines cells with stem celllike characteristics and Mullerian Inhibiting Substance responsiveness," Proceedings of the National Academy of Sciences of the United States of America, vol. 103, no. 30, pp. 11154-11159, 2006.

[29] S. Zhang, C. Balch, M. W. Chan et al., "Identification and characterization of ovarian cancer-initiating cells from primary human tumors," Cancer Research, vol. 68, no. 11, pp. 4311-4320, 2008.

[30] D. Fang, T. K. Nguyen, K. Leishear et al., "A tumorigenic subpopulation with stem cell properties in melanomas," Cancer Research, vol. 65, no. 20, pp. 9328-9337, 2005.

[31] E. Quintana, M. Shackleton, M. S. Sabel, D. R. Fullen, T. M. Johnson, and S. J. Morrison, "Efficient tumour formation by single human melanoma cells," Nature, vol. 456, no. 7222, pp. 593-598, 2008.

[32] T. Schatton, G. F. Murphy, N. Y. Frank et al., "Identification of cells initiating human melanomas," Nature, vol. 451, no. 7176, pp. 345-349, 2008.

[33] M. Salerno, S. Avnet, G. Bonuccelli et al., "Sphere-forming cell subsets with cancer stem cell properties in human musculoskeletal sarcomas," International Journal of Oncology, vol. 43, no. 1, pp. 95-102, 2013.

[34] T. Lapidot, C. Sirard, J. Vormoor et al., "A cell initiating human acute myeloid leukaemia after transplantation into SCID mice," Nature, vol. 367, no. 6464, pp. 645-648, 1994.

[35] T. Baba, P. A. Convery, N. Matsumura et al., "Epigenetic regulation of CD133 and tumorigenicity of CD133+ ovarian cancer cells," Oncogene, vol. 28, no. 2, pp. 209-218, 2009.

[36] E. Monzani, F. Facchetti, E. Galmozzi et al., "Melanoma contains CD133 and ABCG2 positive cells with enhanced tumourigenic 
potential," European Journal of Cancer, vol. 43, no. 5, pp. 935946, 2007.

[37] B. Greve, R. Kelsch, K. Spaniol, H. T. Eich, and M. Götte, "Flow cytometry in cancer stem cell analysis and separation," Cytometry Part A, vol. 81, no. 4, pp. 284-293, 2012.

[38] H. Liu, L. Lv, and K. Yang, "Chemotherapy targeting cancer stem cells," American Journal of Cancer Research, vol. 5, no. 3, pp. 880-893, 2015.

[39] J. P. Medema, "Cancer stem cells: the challenges ahead," Nature Cell Biology, vol. 15, no. 4, pp. 338-344, 2013.

[40] C. Hadjimichael, K. Chanoumidou, N. Papadopoulou, P. Arampatzi, J. Papamatheakis, and A. Kretsovali, "Common stemness regulators of embryonic and cancer stem cells," World Journal of Stem Cells, vol. 7, no. 9, pp. 1150-1184, 2015.

[41] A. Liu, X. Yu, and S. Liu, "Pluripotency transcription factors and cancer stem cells: small genes make a big difference," Chinese Journal of Cancer, vol. 32, no. 9, pp. 483-487, 2013.

[42] S. Lemma, S. Avnet, M. Salerno, T. Chano, N. Baldini, and J. S. Castresana, "Identification and validation of housekeeping genes for gene expression analysis of cancer stem cells," PLoS ONE, vol. 11, no. 2, Article ID e0149481, 2016.

[43] M. Fève, J.-M. Saliou, M. Zeniou et al., "Comparative expression study of the endo-G protein coupled receptor (GPCR) repertoire in human glioblastoma cancer stem-like cells, U87MG cells and non malignant cells of neural origin unveils new potential therapeutic targets," PLoS ONE, vol. 9, no. 3, Article ID e91519, 2014.

[44] M. Zeniou, M. Fève, S. Mameri et al., "Chemical library screening and structure-function relationship studies identify bisacodyl as a potent and selective cytotoxic agent towards quiescent human glioblastoma tumor stem-like cells," PLoS ONE, vol. 10, no. 8, Article ID e0134793, 2015.

[45] H. Clevers, "The cancer stem cell: premises, promises and challenges," Nature Medicine, vol. 17, no. 3, pp. 313-319, 2011.

[46] A. B. Hjelmeland and J. N. Rich, "The quest for self-identity: not all cancer stem cells are the same," Clinical Cancer Research, vol. 18, no. 13, pp. 3495-3498, 2012.

[47] M. Boesch, D. Wolf, and S. Sopper, "Optimized stem cell detection using the DyeCycle-triggered side population phenotype," Stem Cells International, vol. 2016, Article ID 1652389, 14 pages, 2016.

[48] A. Golebiewska, N. H. C. Brons, R. Bjerkvig, and S. P. Niclou, "Critical appraisal of the side population assay in stem cell and cancer stem cell research," Cell Stem Cell, vol. 8, no. 2, pp. 136147, 2011.

[49] V. Richard, M. G. Nair, T. R. Santhosh Kumar, and M. R. Pillai, "Side population cells as prototype of chemoresistant, tumorinitiating cells," BioMed Research International, vol. 2013, Article ID 517237, 8 pages, 2013.

[50] S. Bandhavkar, "Cancer stem cells: a metastasizing menace!," Cancer Medicine, vol. 5, no. 4, pp. 649-655, 2016.

[51] A. Borah, S. Raveendran, A. Rochani, T. Maekawa, and D. S. Kumar, "Targeting self-renewal pathways in cancer stem cells: clinical implications for cancer therapy," Oncogenesis, vol. 4, no. 11, article e177, 2015.

[52] M. Katoh, "Networking of WNT, FGF, Notch, BMP, and Hedgehog signaling pathways during carcinogenesis," Stem Cell Reviews, vol. 3, no. 1, pp. 30-38, 2007.

[53] P. A. Sotiropoulou, M. S. Christodoulou, A. Silvani, C. HeroldMende, and D. Passarella, "Chemical approaches to targeting drug resistance in cancer stem cells," Drug Discovery Today, vol. 19, no. 10, pp. 1547-1562, 2014.
[54] N. Takebe, L. Miele, P. J. Harris et al., "Targeting Notch, Hedgehog, and Wnt pathways in cancer stem cells: clinical update," Nature Reviews Clinical Oncology, vol. 12, no. 8, pp. 445-464, 2015.

[55] B. Ramaswamy, Y. Lu, K.-Y. Teng et al., "Hedgehog signaling is a novel therapeutic target in tamoxifen-resistant breast cancer aberrantly activated by PI3K/AKT pathway," Cancer Research, vol. 72, no. 19, pp. 5048-5059, 2012.

[56] R. L. Yauch, G. J. P. Dijkgraaf, B. Alicke et al., "Smoothened mutation confers resistance to a hedgehog pathway inhibitor in medulloblastoma," Science, vol. 326, no. 5952, pp. 572-574, 2009.

[57] A. E. Sloan, C. J. Nock, X. B. Ye et al., "Targeting gliomainitiating cells in GBM: ABTC-0904, a randomized phase 0/II study targeting the Sonic Hedgehog-signaling pathway," Journal of Clinical Oncology, vol. 32, abstract 2026, 2014, Proceedings of the 2014 ASCO Annual Meeting.

[58] A. N. Hata, J. A. Engelman, and A. C. Faber, "The BCL2 family: key mediators of the apoptotic response to targeted anticancer therapeutics," Cancer Discovery, vol. 5, no. 5, pp. 475-487, 2015.

[59] D. Capper, T. Gaiser, C. Hartmann et al., "Stem-cell-like glioma cells are resistant to TRAIL/Apo2L and exhibit down-regulation of caspase- 8 by promoter methylation," Acta Neuropathologica, vol. 117, no. 4, pp. 445-456, 2009.

[60] F. Jin, L. Zhao, H.-Y. Zhao et al., "Comparison between cells and cancer stem-like cells isolated from glioblastoma and astrocytoma on expression of anti-apoptotic and multidrug resistance-associated protein genes," Neuroscience, vol. 154, no. 2, pp. 541-550, 2008.

[61] G. P. Dunn, M. L. Rinne, J. Wykosky et al., "Emerging insights into the molecular and cellular basis of glioblastoma," Genes and Development, vol. 26, no. 8, pp. 756-784, 2012.

[62] F. B. Furnari, T. Fenton, R. M. Bachoo et al., "Malignant astrocytic glioma: genetics, biology, and paths to treatment," Genes \& Development, vol. 21, no. 21, pp. 2683-2710, 2007.

[63] K. E. Tagscherer, A. Fassl, B. Campos et al., "Apoptosisbased treatment of glioblastomas with ABT-737, a novel small molecule inhibitor of Bcl-2 family proteins," Oncogene, vol. 27, no. 52, pp. 6646-6656, 2008.

[64] L. Piggott, N. Omidvar, S. Martí Pérez, R. French, M. Eberl, and R. W. Clarkson, "Suppression of apoptosis inhibitor c-FLIP selectively eliminates breast cancer stem cell activity in response to the anti-cancer agent, TRAIL," Breast Cancer Research, vol. 13, no. 5, article R88, 2011.

[65] Y.-P. Yang, Y. Chien, G.-Y. Chiou et al., "Inhibition of cancer stem cell-like properties and reduced chemoradioresistance of glioblastoma using microRNA145 with cationic polyurethaneshort branch PEI," Biomaterials, vol. 33, no. 5, pp. 1462-1476, 2012.

[66] Q. E. Wang, "DNA damage responses in cancer stem cells: implications for cancer therapeutic strategies," World Journal of Biological Chemistry, vol. 6, no. 3, pp. 57-64, 2015.

[67] S. Bao, Q. Wu, R. E. McLendon et al., "Glioma stem cells promote radioresistance by preferential activation of the DNA damage response," Nature, vol. 444, no. 7120, pp. 756-760, 2006.

[68] V. A. Venkatesha, L. A. Parsels, J. D. Parsels et al., "Sensitization of pancreatic cancer stem cells to gemcitabine by Chk1 inhibition," Neoplasia, vol. 14, no. 6, pp. 519-525, 2012.

[69] S. Facchino, M. Abdouh, W. Chatoo, and G. Bernier, "BMI1 confers radioresistance to normal and cancerous neural stem cells through recruitment of the DNA damage response machinery," Journal of Neuroscience, vol. 30, no. 30, pp. 10096-10111, 2010. 
[70] Y.-C. Chen, C.-J. Chang, H.-S. Hsu et al., "Inhibition of tumorigenicity and enhancement of radiochemosensitivity in head and neck squamous cell cancer-derived ALDH1-positive cells by knockdown of Bmi-1," Oral Oncology, vol. 46, no. 3, pp. 158-165, 2010.

[71] G. Liu, X. Yuan, Z. Zeng et al., "Analysis of gene expression and chemoresistance of CD133+ cancer stem cells in glioblastoma," Molecular Cancer, vol. 5, article 67, 2006.

[72] L. A. Mathews, S. M. Cabarcas, E. M. Hurt, X. Zhang, E. M. Jaffee, and W. L. Farrar, "Increased expression of DNA repair genes in invasive human pancreatic cancer cells," Pancreas, vol. 40, no. 5, pp. 730-739, 2011.

[73] C.-H. Chang, M. Zhang, K. Rajapakshe et al., "Mammary stem cells and tumor-initiating cells are more resistant to apoptosis and exhibit increased DNA repair activity in response to DNA damage," Stem Cell Reports, vol. 5, no. 3, pp. 378-391, 2015.

[74] E. Singer, J. Judkins, N. Salomonis et al., "Reactive oxygen species-mediated therapeutic response and resistance in glioblastoma," Cell Death and Disease, vol. 6, no. 1, Article ID e1601, 2015.

[75] L. Chang, P. Graham, J. Hao et al., "Cancer stem cells and signaling pathways in radioresistance," Oncotarget, vol. 7, no. 10, pp. 11002-11017, 2016.

[76] S. Ding, C. Li, N. Cheng, X. Cui, X. Xu, and G. Zhou, "Redox regulation in cancer stem cells," Oxidative Medicine and Cellular Longevity, vol. 2015, Article ID 750798, 11 pages, 2015.

[77] V. J. Bhagwandin, J. M. Bishop, W. E. Wright, and J. W. Shay, "The metastatic potential and chemoresistance of human pancreatic cancer stem cells," PLoS ONE, vol. 11, no. 2, Article ID e0148807, 2016.

[78] T. Chiba, K. Kita, Y.-W. Zheng et al., "Side population purified from hepatocellular carcinoma cells harbors cancer stem celllike properties," Hepatology, vol. 44, no. 1, pp. 240-251, 2006.

[79] J. Liu, N. Chi, J. Y. Zhang, W. Zhu, Y. S. Bian, and H. G. Chen, "Isolation and characterization of cancer stem cells from medulloblastoma," Genetics and Molecular Research, vol. 14, no. 2, pp. 3355-3361, 2015.

[80] C. Di and Y. Zhao, "Multiple drug resistance due to resistance to stem cells and stem cell treatment progress in cancer," Experimental and Therapeutic Medicine, vol. 9, no. 2, pp. 289293, 2015.

[81] D. L. Dragu, L. G. Necula, C. Bleotu, C. C. Diaconu, and M. Chivu-Economescu, "Therapies targeting cancer stem cells: current trends and future challenges," World Journal of Stem Cells, vol. 7, no. 9, pp. 1185-1201, 2015.

[82] S. Karthikeyan and S. L. Hoti, "Development of fourth generation $\mathrm{ABC}$ inhibitors from natural products: a novel approach to overcome cancer multidrug resistance," Anti-Cancer Agents in Medicinal Chemistry, vol. 15, no. 5, pp. 605-615, 2015.

[83] D. R. Pattabiraman and R. A. Weinberg, "Tackling the cancer stem cells-what challenges do they pose?" Nature Reviews Drug Discovery, vol. 13, no. 7, pp. 497-512, 2014.

[84] S. G. M. Piccirillo, B. A. Reynolds, N. Zanetti et al., "Bone morphogenetic proteins inhibit the tumorigenic potential of human brain tumour-initiating cells," Nature, vol. 444, no. 7120, pp. 761-765, 2006.

[85] J. Lee, M. J. Son, K. Woolard et al., "Epigenetic-mediated dysfunction of the bone morphogenetic protein pathway inhibits differentiation of glioblastoma-initiating cells," Cancer Cell, vol. 13, no. 1, pp. 69-80, 2008.
[86] V. Balasubramaniyan, B. Vaillant, S. Wang et al., "Aberrant mesenchymal differentiation of glioma stem-like cells: implications for therapeutic targeting," Oncotarget, vol. 6, no. 31, pp. 3100731017, 2015.

[87] T. H. Cheung and T. A. Rando, "Molecular regulation of stem cell quiescence," Nature Reviews Molecular Cell Biology, vol. 14, no. 6, pp. 329-340, 2013.

[88] B. Martynoga, J. L. Mateo, B. Zhou et al., "Epigenomic enhancer annotation reveals a key role for NFIX in neural stem cell quiescence," Genes and Development, vol. 27, no. 16, pp. 17691786, 2013.

[89] J.-H. Paik, Z. Ding, R. Narurkar et al., "FoxOs cooperatively regulate diverse pathways governing neural stem cell homeostasis," Cell Stem Cell, vol. 5, no. 5, pp. 540-553, 2009.

[90] J. R. Valcourt, J. M. S. Lemons, E. M. Haley, M. Kojima, O. O. Demuren, and H. A. Coller, "Staying alive: metabolic adaptations to quiescence," Cell Cycle, vol. 11, no. 9, pp. 16801696, 2012.

[91] S. H. Wang and S. Lin, "Tumor dormancy: potential therapeutic target in tumor recurrence and metastasis prevention," Experimental Hematology \& Oncology, vol. 2, no. 1, article 29, 2013.

[92] M. S. Sosa, P. Bragado, and J. A. Aguirre-Ghiso, "Mechanisms of disseminated cancer cell dormancy: an awakening field," Nature Reviews Cancer, vol. 14, no. 9, pp. 611-622, 2014.

[93] J. L. Dembinski and S. Krauss, "Characterization and functional analysis of a slow cycling stem cell-like subpopulation in pancreas adenocarcinoma," Clinical and Experimental Metastasis, vol. 26, no. 7, pp. 611-623, 2009.

[94] S. Pece, D. Tosoni, S. Confalonieri et al., "Biological and molecular heterogeneity of breast cancers correlates with their cancer stem cell content," Cell, vol. 140, no. 1, pp. 62-73, 2010.

[95] N. Haraguchi, H. Ishii, K. Mimori et al., "CD13 is a therapeutic target in human liver cancer stem cells," The Journal of Clinical Investigation, vol. 120, no. 9, pp. 3326-3339, 2010.

[96] A. Roesch, M. Fukunaga-Kalabis, E. C. Schmidt et al., "A temporarily distinct subpopulation of slow-cycling melanoma cells is required for continuous tumor growth," Cell, vol. 141, no. 4, pp. 583-594, 2010.

[97] M.-Q. Gao, Y.-P. Choi, S. Kang, J. H. Youn, and N.-H. Cho, "CD24 ${ }^{+}$cells from hierarchically organized ovarian cancer are enriched in cancer stem cells," Oncogene, vol. 29, no. 18, pp. 2672-2680, 2010.

[98] Z. Vincent, K. Urakami, K. Maruyama, K. Yamaguchi, and M. Kusuhara, "CD133-positive cancer stem cells from Colo205 human colon adenocarcinoma cell line show resistance to chemotherapy and display a specific metabolomic profile," Genes \& Cancer, vol. 5, no. 7-8, pp. 250-260, 2014.

[99] L. P. Deleyrolle, A. Harding, K. Cato et al., "Evidence for labelretaining tumour-initiating cells in human glioblastoma," Brain, vol. 134, no. 5, pp. 1331-1343, 2011.

[100] J. Chen, Y. Li, T.-S. Yu et al., "A restricted cell population propagates glioblastoma growth after chemotherapy," Nature, vol. 488, no. 7412, pp. 522-526, 2012.

[101] A. P. Patel, I. Tirosh, J. J. Trombetta et al., "Single-cell RNA-seq highlights intratumoral heterogeneity in primary glioblastoma," Science, vol. 344, no. 6190, pp. 1396-1401, 2014.

[102] A. Ishii, T. Kimura, H. Sadahiro et al., "Histological characterization of the tumorigenic 'Peri-Necrotic Niche' harboring quiescent stem-like tumor cells in glioblastoma," PLoS ONE, vol. 11, no. 1, Article ID e0147366, 2016. 
[103] S. Takeishi, A. Matsumoto, I. Onoyama, K. Naka, A. Hirao, and K. I. Nakayama, "Ablation of Fbxw7 eliminates leukemiainitiating cells by preventing quiescence," Cancer Cell, vol. 23, no. 3, pp. 347-361, 2013.

[104] Y. Saito, N. Uchida, S. Tanaka et al., "Induction of cell cycle entry eliminates human leukemia stem cells in a mouse model of AML," Nature Biotechnology, vol. 28, no. 3, pp. 275-280, 2010.

[105] A. P. Adam, A. George, D. Schewe et al., "Computational identification of a p38 SAPK-regulated transcription factor network required for tumor cell quiescence," Cancer Research, vol. 69, no. 14, pp. 5664-5672, 2009.

[106] P. Bragado, Y. Estrada, F. Parikh et al., "TGF- $\beta 2$ dictates disseminated tumour cell fate in target organs through TGF- $\beta$ RIII and p38 $\alpha / \beta$ signalling," Nature Cell Biology, vol. 15, no. 11, pp. 1351-1361, 2013.

[107] A. Kobayashi, H. Okuda, F. Xing et al., "Bone morphogenetic protein 7 in dormancy and metastasis of prostate cancer stemlike cells in bone," The Journal of Experimental Medicine, vol. 208, no. 13, pp. 2641-2655, 2011.

[108] M. C. Cabrera, R. E. Hollingsworth, and E. M. Hurt, "Cancer stem cell plasticity and tumor hierarchy," World Journal of Stem Cells, vol. 7, no. 1, pp. 27-36, 2015.

[109] A. Avgustinova and S. A. Benitah, "The epigenetics of tumour initiation: cancer stem cells and their chromatin," Current Opinion in Genetics \& Development, vol. 36, pp. 8-15, 2016.

[110] A. O. Pisco and S. Huang, "Non-genetic cancer cell plasticity and therapy-induced stemness in tumour relapse: 'what does not kill me strengthens me"' British Journal of Cancer, vol. 112, no. 11, pp. 1725-1732, 2015.

[111] E. Quintana, M. Shackleton, H. R. Foster et al., "Phenotypic heterogeneity among tumorigenic melanoma cells from patients that is reversible and not hierarchically organized," Cancer Cell, vol. 18, no. 5, pp. 510-523, 2010.

[112] M. L. Suvà, E. Rheinbay, S. M. Gillespie et al., "Reconstructing and reprogramming the tumor-propagating potential of glioblastoma stem-like cells," Cell, vol. 157, no. 3, pp. 580-594, 2014.

[113] N. Oshima, Y. Yamada, S. Nagayama et al., "Induction of cancer stem cell properties in colon cancer cells by defined factors," PLoS ONE, vol. 9, no. 7, Article ID e101735, 2014.

[114] M. R. Junttila and F. J. de Sauvage, "Influence of tumour microenvironment heterogeneity on therapeutic response," Nature, vol. 501, no. 7467, pp. 346-354, 2013.

[115] L. Lacina, J. Plzak, O. Kodet et al., "Cancer microenvironment: what can we learn from the stem cell niche," International Journal of Molecular Sciences, vol. 16, no. 10, pp. 24094-24110, 2015.

[116] V. Plaks, N. Kong, and Z. Werb, “The cancer stem cell niche: how essential is the niche in regulating stemness of tumor cells?" Cell Stem Cell, vol. 16, no. 3, pp. 225-238, 2015.

[117] M. A. LaBarge, "The difficulty of targeting cancer stem cell niches," Clinical Cancer Research, vol. 16, no. 12, pp. 3121-3129, 2010.

[118] H. C. Chong, C. K. Tan, R.-L. Huang, and N. S. Tan, "Matricellular proteins: a sticky affair with cancers," Journal of Oncology, vol. 2012, Article ID 351089, 17 pages, 2012.

[119] P. Lu, V. M. Weaver, and Z. Werb, “The extracellular matrix: a dynamic niche in cancer progression," The Journal of Cell Biology, vol. 196, no. 4, pp. 395-406, 2012.

[120] F. M. Watt and W. T. S. Huck, "Role of the extracellular matrix in regulating stem cell fate," Nature Reviews Molecular Cell Biology, vol. 14, no. 8, pp. 467-473, 2013.
[121] C. Farace, J. A. Oliver, C. Melguizo et al., "Microenvironmental modulation of decorin and lumican in temozolomide-resistant glioblastoma and neuroblastoma cancer stem-like cells," PLoS ONE, vol. 10, no. 7, Article ID e0134111, 2015.

[122] E. Fessler, T. Borovski, and J. P. Medema, "Endothelial cells induce cancer stem cell features in differentiated glioblastoma cells via bFGF," Molecular Cancer, vol. 14, article 157, 2015.

[123] A. Singh and J. Settleman, "EMT, cancer stem cells and drug resistance: an emerging axis of evil in the war on cancer," Oncogene, vol. 29, no. 34, pp. 4741-4751, 2010.

[124] J. P. Thiery and J. P. Sleeman, "Complex networks orchestrate epithelial-mesenchymal transitions," Nature Reviews Molecular Cell Biology, vol. 7, no. 2, pp. 131-142, 2006.

[125] M. R. Doherty, J. M. Smigiel, D. J. Junk, and M. W. Jackson, "Cancer stem cell plasticity drives therapeutic resistance," Cancers (Basel), vol. 8, no. 1, p. 8, 2016.

[126] S. A. Mani, W. Guo, M.-J. Liao et al., "The epithelialmesenchymal transition generates cells with properties of stem cells," Cell, vol. 133, no. 4, pp. 704-715, 2008.

[127] A. Mitra, L. Mishra, and S. Li, "EMT, CTCs and CSCs in tumor relapse and drug-resistance," Oncotarget, vol. 6, no. 13, pp. 10697-10711, 2015.

[128] F. Andriani, G. Bertolini, F. Facchinetti et al., "Conversion to stem-cell state in response to microenvironmental cues is regulated by balance between epithelial and mesenchymal features in lung cancer cells," Molecular Oncology, vol. 10, no. 2, pp. 253-271, 2016.

[129] I. Kryczek, Y. Lin, N. Nagarsheth et al., "IL-22 $2^{+} \mathrm{CD} 4^{+} \mathrm{T}$ cells promote colorectal cancer stemness via STAT3 transcription factor activation and induction of the methyltransferase DOT1L," Immunity, vol. 40, no. 5, pp. 772-784, 2014.

[130] M. Santisteban, J. M. Reiman, M. K. Asiedu et al., "Immuneinduced epithelial to mesenchymal transition in vivo generates breast cancer stem cells," Cancer Research, vol. 69, no. 7, pp. 2887-2895, 2009.

[131] S. Hamada, A. Masamune, T. Takikawa et al., "Pancreatic stellate cells enhance stem cell-like phenotypes in pancreatic cancer cells," Biochemical and Biophysical Research Communications, vol. 421, no. 2, pp. 349-354, 2012.

[132] E. Lonardo, J. Frias-Aldeguer, P. C. Hermann, and C. Heeschen, "Pancreatic stellate cells form a niche for cancer stem cells and promote their self-renewal and invasiveness," Cell Cycle, vol. 11, no. 7, pp. 1282-1290, 2012.

[133] J. Evans, A. Essex, H. Xin, N. Amitai, L. Brinton, and E. Griner, "Registered report: Wnt activity defines colon cancer stem cells and is regulated by the microenvironment," eLife, vol. 4, Article ID e07301, 2015.

[134] L. Vermeulen, F. De Sousa E Melo, M. van der Heijden et al., "Wnt activity defines colon cancer stem cells and is regulated by the microenvironment," Nature Cell Biology, vol. 12, no. 5, pp. 468-476, 2010.

[135] J. A. Bertout, S. A. Patel, and M. C. Simon, “The impact of $\mathrm{O}_{2}$ availability on human cancer," Nature Reviews Cancer, vol. 8, no. 12, pp. 967-975, 2008.

[136] N. C. Denko, "Hypoxia, HIF1 and glucose metabolism in the solid tumour," Nature Reviews Cancer, vol. 8, no. 9, pp. 705-713, 2008.

[137] E. Paolicchi, F. Gemignani, M. Krstic-Demonacos, S. Dedhar, L. Mutti, and S. Landi, "Targeting hypoxic response for cancer therapy," Oncotarget, vol. 7, no. 12, pp. 13464-13478, 2016. 
[138] B. Philip, K. Ito, R. Moreno-Sánchez, and S. J. Ralph, "HIF expression and the role of hypoxic microenvironments within primary tumours as protective sites driving cancer stem cell renewal and metastatic progression," Carcinogenesis, vol. 34, no. 8, pp. 1699-1707, 2013.

[139] J. M. Heddleston, Z. Li, J. D. Lathia, S. Bao, A. B. Hjelmeland, and J. N. Rich, "Hypoxia inducible factors in cancer stem cells," British Journal of Cancer, vol. 102, no. 5, pp. 789-795, 2010.

[140] Y. Kim, Q. Lin, P. M. Glazer, and Z. Yun, "Hypoxic tumor microenvironment and cancer cell differentiation," Current Molecular Medicine, vol. 9, no. 4, pp. 425-434, 2009.

[141] J. Mathieu, Z. Zhang, W. Zhou et al., "HIF induces human embryonic stem cell markers in cancer cells," Cancer Research, vol. 71, no. 13, pp. 4640-4652, 2011.

[142] J. M. Heddleston, Z. Li, R. E. McLendon, A. B. Hjelmeland, and J. N. Rich, "The hypoxic microenvironment maintains glioblastoma stem cells and promotes reprogramming towards a cancer stem cell phenotype," Cell Cycle, vol. 8, no. 20, pp. 32743284, 2009.

[143] Z. Li, S. Bao, Q. Wu et al., "Hypoxia-inducible factors regulate tumorigenic capacity of glioma stem cells," Cancer Cell, vol. 15, no. 6, pp. 501-513, 2009.

[144] K. Helczynska, Å. Kronblad, A. Jögi et al., "Hypoxia promotes a dedifferentiated phenotype in ductal breast carcinoma in situ," Cancer Research, vol. 63, no. 7, pp. 1441-1444, 2003.

[145] E. Louie, S. Nik, J.-S. Chen et al., "Identification of a stem-like cell population by exposing metastatic breast cancer cell lines to repetitive cycles of hypoxia and reoxygenation," Breast Cancer Research, vol. 12, no. 6, article R94, 2010.

[146] B. Das, R. Tsuchida, D. Malkin, G. Koren, S. Baruchel, and H. Yeger, "Hypoxia enhances tumor stemness by increasing the invasive and tumorigenic side population fraction," STEM CELLS, vol. 26, no. 7, pp. 1818-1830, 2008.

[147] N. Platet, S. Y. Liu, M. E. Atifi et al., "Influence of oxygen tension on CD133 phenotype in human glioma cell cultures," Cancer Letters, vol. 258, no. 2, pp. 286-290, 2007.

[148] R. P. Hill, D. T. Marie-Egyptienne, and D. W. Hedley, "Cancer stem cells, hypoxia and metastasis," Seminars in Radiation Oncology, vol. 19, no. 2, pp. 106-111, 2009.

[149] T. van den Beucken, E. Koch, K. Chu et al., "Hypoxia promotes stem cell phenotypes and poor prognosis through epigenetic regulation of DICER," Nature Communications, vol. 5, article 5203, 2014.

[150] Y. J. Yang, H. J. Na, M. J. Suh et al., "Hypoxia induces epithelial-mesenchymal transition in follicular thyroid cancer: involvement of regulation of twist by hypoxia inducible factor1 $\alpha$," Yonsei Medical Journal, vol. 56, no. 6, pp. 1503-1514, 2015.

[151] J. Guo, B. Wang, Z. Fu, J. Wei, and W. Lu, "Hypoxic microenvironment induces EMT and upgrades stem-like properties of gastric cancer cells," Technology in Cancer Research \& Treatment, vol. 15, no. 1, pp. 60-68, 2016.

[152] S. Liu, S. M. Kumar, J. S. Martin, R. Yang, and X. Xu, "Snaill mediates hypoxia-induced melanoma progression," The American Journal of Pathology, vol. 179, no. 6, pp. 3020-3031, 2011.

[153] J. Chiche, M. C. Brahimi-Horn, and J. Pouysségur, “Tumour hypoxia induces a metabolic shift causing acidosis: a common feature in cancer," Journal of Cellular and Molecular Medicine, vol. 14, no. 4, pp. 771-794, 2010.

[154] A. B. Hjelmeland, Q. Wu, J. M. Heddleston et al., "Acidic stress promotes a glioma stem cell phenotype," Cell Death and Differentiation, vol. 18, no. 5, pp. 829-840, 2011.
[155] C. Lagadec, E. Vlashi, L. Della Donna, C. Dekmezian, and F. Pajonk, "Radiation-induced reprogramming of breast cancer cells," STEM CELLS, vol. 30, no. 5, pp. 833-844, 2012.

[156] C. Nör, Z. C. Zhang, K. A. Warner et al., "Cisplatin induces Bmi1 and enhances the stem cell fraction in head and neck cancer," Neoplasia, vol. 16, no. 2, pp. 137-146, 2014.

[157] A. Roesch, A. Vultur, I. Bogeski et al., "Overcoming intrinsic multidrug resistance in melanoma by blocking the mitochondrial respiratory chain of slow-cycling JARID1B(high) cells," Cancer Cell, vol. 23, no. 6, pp. 811-825, 2013.

[158] C. Denise, P. Paoli, M. Calvani et al., "5-Fluorouracil resistant colon cancer cells are addicted to OXPHOS to survive and enhance stem-like traits," Oncotarget, vol. 6, no. 39, pp. 4170641721, 2015.

[159] S. Vanharanta and J. Massagué, "Origins of metastatic traits," Cancer Cell, vol. 24, no. 4, pp. 410-421, 2013.

[160] L. Wan, K. Pantel, and Y. Kang, "Tumor metastasis: moving new biological insights into the clinic," Nature Medicine, vol. 19, no. 11, pp. 1450-1464, 2013.

[161] S. Kimbung, N. Loman, and I. Hedenfalk, "Clinical and molecular complexity of breast cancer metastases," Seminars in Cancer Biology, vol. 35, pp. 85-95, 2015.

[162] I. Baccelli, A. Schneeweiss, S. Riethdorf et al., "Identification of a population of blood circulating tumor cells from breast cancer patients that initiates metastasis in a xenograft assay," Nature Biotechnology, vol. 31, no. 6, pp. 539-544, 2013.

[163] T. Hiraga, S. Ito, and H. Nakamura, "Cancer stem-like cell marker CD44 promotes bone metastases by enhancing tumorigenicity, cell motility, and hyaluronan production," Cancer Research, vol. 73, no. 13, pp. 4112-4122, 2013.

[164] C. van den Hoogen, G. van der Horst, H. Cheung et al., "High aldehyde dehydrogenase activity identifies tumor-initiating and metastasis-initiating cells in human prostate cancer," Cancer Research, vol. 70, no. 12, pp. 5163-5173, 2010.

[165] D. A. Lawson, N. R. Bhakta, K. Kessenbrock et al., "Single-cell analysis reveals a stem-cell program in human metastatic breast cancer cells," Nature, vol. 526, no. 7571, pp. 131-135, 2015.

[166] I. Malanchi, A. Santamaria-Martínez, E. Susanto et al., "Interactions between cancer stem cells and their niche govern metastatic colonization," Nature, vol. 481, no. 7379, pp. 85-91, 2012. 

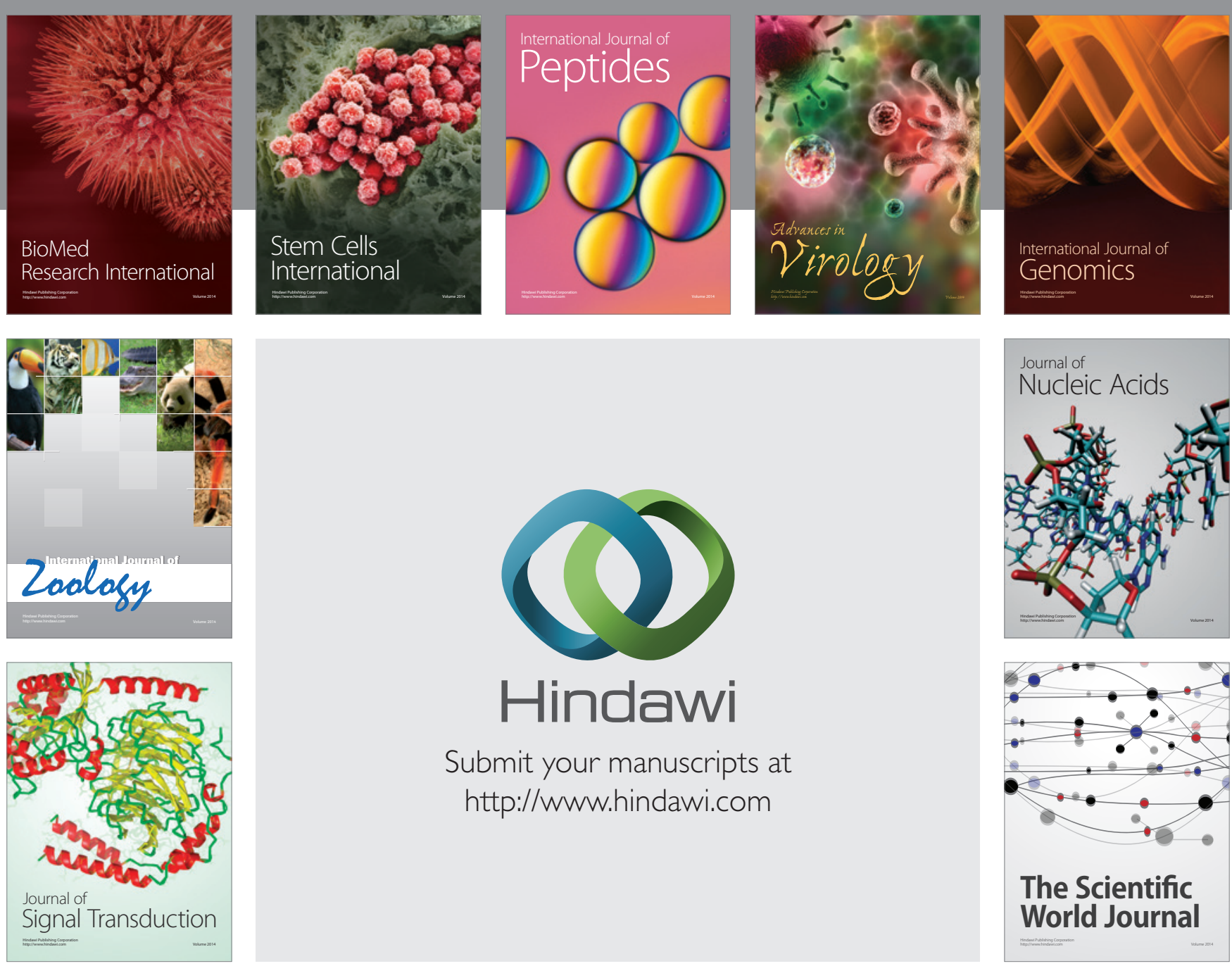

Submit your manuscripts at

http://www.hindawi.com
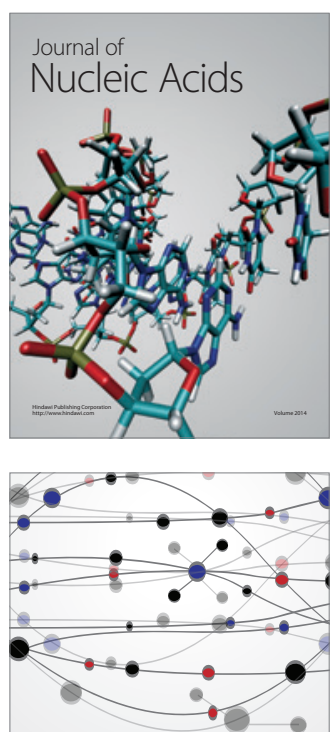

The Scientific World Journal
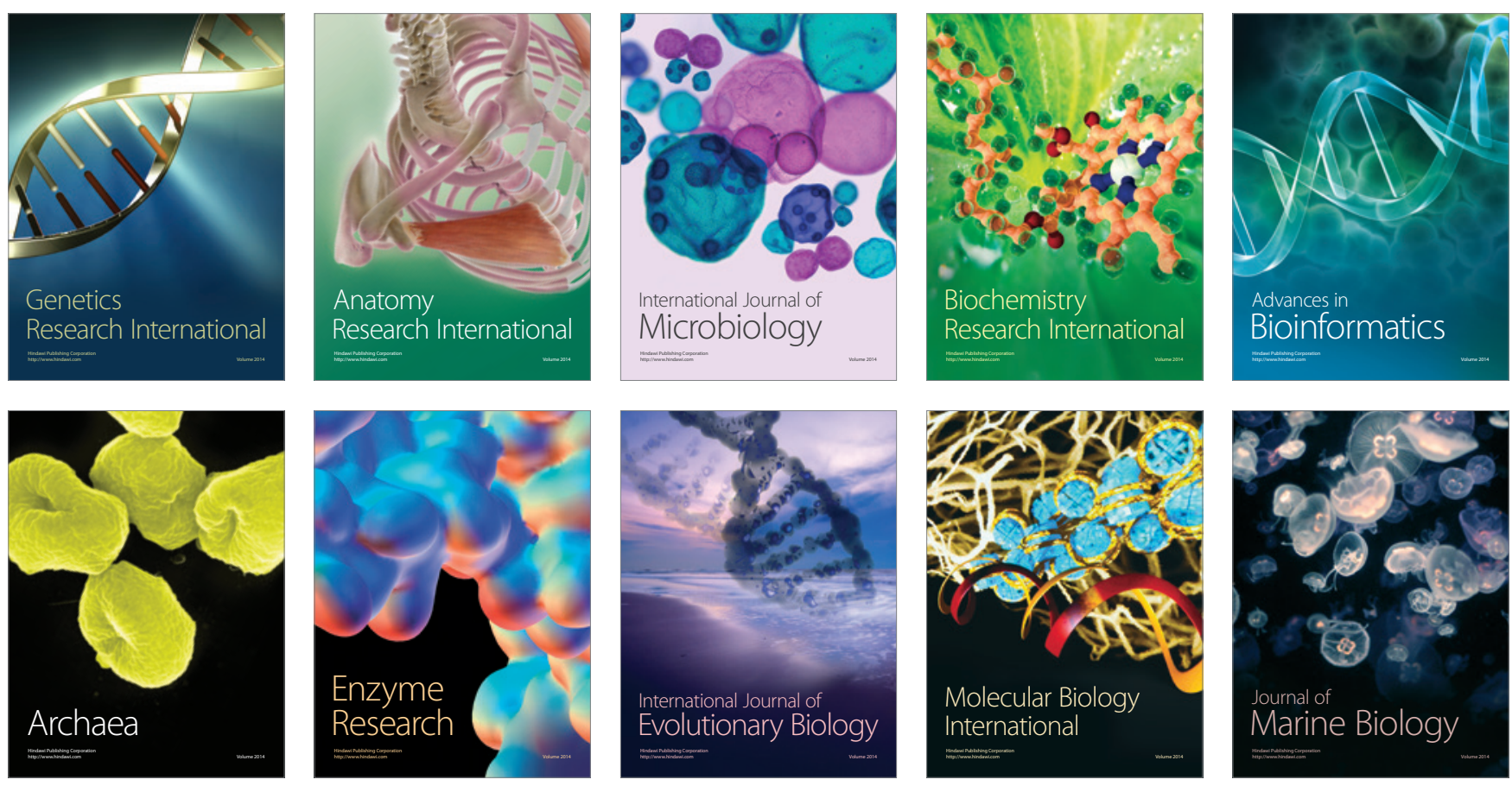